Portland State University

PDXScholar

$1-1-2011$

\title{
Tree Growth and Spatial Pattern in Two Forest Park Permanent Plots: A Look at Stand Composition and Condition
}

Hannah Beth McDonald

Portland State University

Follow this and additional works at: https://pdxscholar.library.pdx.edu/open_access_etds Let us know how access to this document benefits you.

Recommended Citation

McDonald, Hannah Beth, "Tree Growth and Spatial Pattern in Two Forest Park Permanent Plots: A Look at Stand Composition and Condition" (2011). Dissertations and Theses. Paper 313.

https://doi.org/10.15760/etd.313

This Thesis is brought to you for free and open access. It has been accepted for inclusion in Dissertations and Theses by an authorized administrator of PDXScholar. Please contact us if we can make this document more accessible: pdxscholar@pdx.edu. 
Tree Growth and Spatial Pattern in Two Forest Park Permanent Plots:

A Look at Stand Composition and Condition

by

Hannah Beth McDonald

A thesis submitted in partial fulfillment of the requirements for the degree of

Master of Science

in

Environmental Science and Management

Thesis Committee:

Marion Dresner, Chair

Robert Scheller

Todd Rosenstiel

Portland State University

(C) 2012 


\begin{abstract}
In June of 2010, two permanent research plots were established in Forest Park, based on their differing proximities to downtown Portland, Oregon. As part of a longterm ecological research project that seeks to explore the ecological status and human thumbprint on this 5,100 acre forested reserve, the 2010 tree data was investigated for emergent compositional and spatial patterns. Stand composition, tree size, growth rates, and spatial patterns were analyzed, along with ecological and land use histories. Results indicate that the Balch plot, more closely located to the urban center, has different stand composition, condition, and vegetation growth rates, compared to the more rural Miller site. This study supports findings from a study done by Broshot in 2009, where more urban plots demonstrate a different stand composition and recruitment pattern than rural sites. The study is an initial step for exploring questions regarding the ecological status of Forest Park and how land use and disturbance, past and present, shape Portland's forested reserve.
\end{abstract}




\section{ACKNOWLEDGEMENTS}

I would like to thank Dr. Marion Dresner for her support and assistance, not only throughout this thesis endeavor, but also throughout my entire graduate school career. Without her guidance, flexibility, and patience in this project, I would be leaving PSU a lesser person. I would also like to thank my parents, Beth and David, and my brother, Sam, for their encouragement and validation, that yes; I would one day complete this undertaking. Without Kathryn Strawn this project would have had twice the tonnage and half the substance, and I thank her for her role in data collection, data mapping, and making the last year and a half exponentially more enjoyable. Thanks must also be extended to her marvelous partner, Sarah Levy, for her support of me via supporting Katy. I give a huge thanks to Kelly and Eric Fischer for their humor and companionship

over the last several years. And a huge thanks to Jay Sexton, Kerissa Fuccillo, Tim Elder, Monique Leslie, John Rueter, Cat de Rivera, \& Brian Turner for their various contributions to this project, my education, and my overall sanity. I thank Rob Scheller and Todd Rosenstiel for their patience through multiple breakdowns and for their guidance in making this project scientifically sound. And finally, I give thanks to Sam Schrager because he is the most supportive, tolerant, and kindhearted man I have ever met. Without his patience to balance my hastiness, I may have internally or externally combusted. 


\section{TABLE OF CONTENTS}

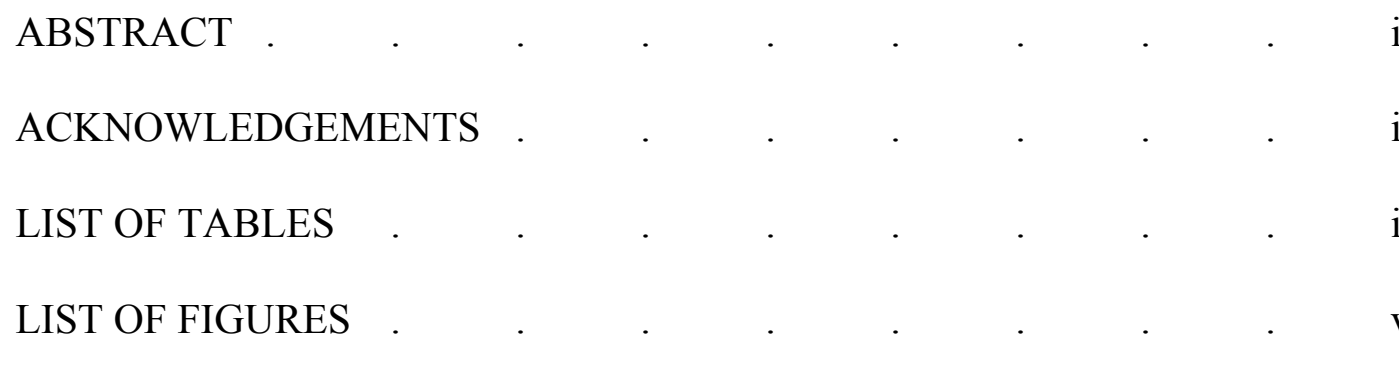

CHAPTER 1:

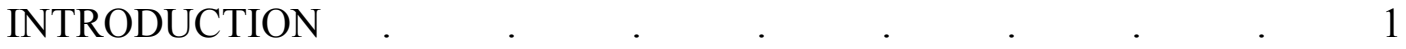

CHAPTER 2:

ECOLOGICAL AND LAND USE HISTORY IN FOREST PARK . 18

CHAPTER 3:

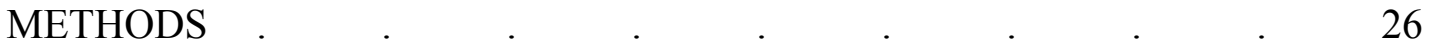

CHAPTER 4:

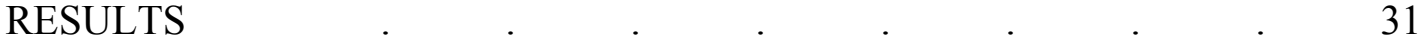

CHAPTER 5:

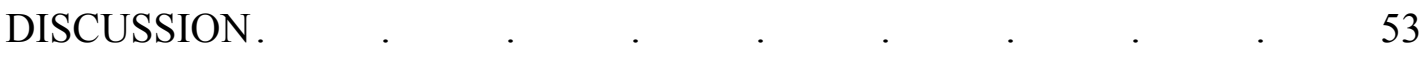

CHAPTER 6:

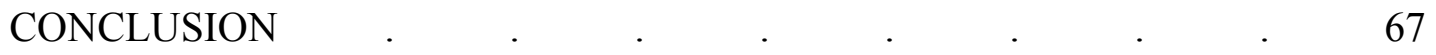

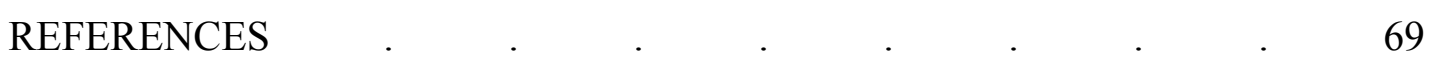




\section{LIST OF TABLES}

4.9: A table of the mean and median ages for P. menziesii and T. heterophylla in the Balch and Miller plots, and the mean and median ages of all dated cores

4.15: A table of the mean and median dbh values for the dominant tree species in the Balch and Miller plots and two-sample t-test results from a statistical comparison of

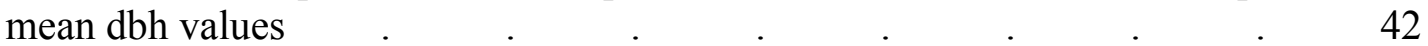

4.17: A table of the mean and median height values for the dominant tree species in the Balch and Miller plots and two-sample t-test results from a statistical comparison of

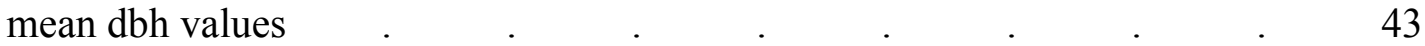




\section{LIST OF FIGURES}

2.1: Overview map of Forest Park, Portland, Oregon $\quad . \quad$. $\quad . \quad 18$

2.2: Map or the area burned in the 1889 fire . $\quad . \quad$. $\quad . \quad$. 20

2.3: Map of the area burned in the 1940 fire . $\quad . \quad$. $\quad . \quad$. 22

2.4: The residential development within and surrounding Forest Park from 1870

to 2004 (North end of the park) . . . . . . . . . $\quad$. 23

2.5: The residential development within and surrounding Forest Park from 1870

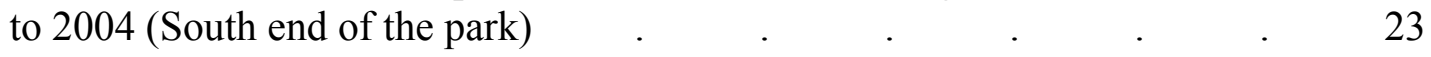

2.6: Map of the burned area in the 1951 fire . $\quad . \quad$. $\quad . \quad$. 24

2.7: Map of the three major fires to occur in Forest Park since 1850. . $\quad 24$

3.1: Map of Forest Park with the locations of the Balch and Miller permanent

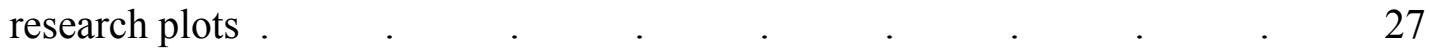

4.1: Scatter plot matrix of tree height $(\mathrm{cm})$ over tree $\mathrm{dbh}(\mathrm{cm})$ for predominate tree species in the Balch permanent plot . $\quad . \quad$. $\quad . \quad . \quad . \quad 31$

4.2: Scatter plot matrix of tree height $(\mathrm{cm})$ over tree $\mathrm{dbh}(\mathrm{cm})$ for predominate tree

species in the Miller permanent plot . $\quad . \quad$. $\quad . \quad$. $\quad$. 32

4.3: Scatter plot matrix of tree height $(\mathrm{cm})$ over tree $\mathrm{dbh}(\mathrm{cm})$ for dominant conifer

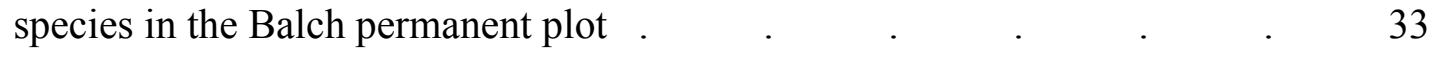

4.4: Scatter plot matrix of tree height $(\mathrm{cm})$ over tree $\mathrm{dbh}(\mathrm{cm})$ for dominant conifer

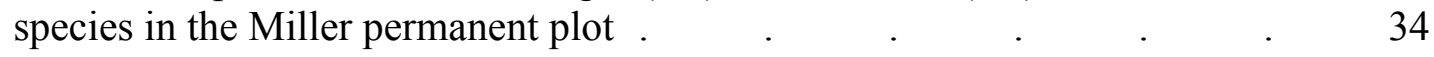

4.5: Bar graph of the ages determined from tree rings in P. menziesii and

T. heterophylla species in the Balch plot . $\quad . \quad$. $\quad . \quad 35$

4.6: Bar graphs of the ages determined from tree rings in P. menziesii and

T. heterophylla species in the Miller plot . $\quad . \quad$. $\quad . \quad$. 35

4.7: Scatter plots of tree height and tree dbh as a function of age in the Balch and

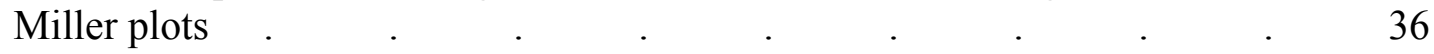

4.8: Bar graph of age class distribution for all dated trees in the Balch and Miller plots 
4.10: Average mean growth rates of T. heterophylla in the Balch and Miller plots 39

4.11: Average mean growth rates of P. menziesii in the Balch and Miller plots 39

4.12: A histogram of every tree dbh in Balch. $\quad . \quad$. $\quad . \quad$. 40

4.13: A histogram of every tree dbh in Miller $\quad . \quad$. $\quad . \quad$. $\quad$. 40

4.14: Mean dbh by species for trees in the Balch and Miller plots $\quad . \quad$. $\quad 41$

4.16: Mean height by species for trees in the Balch and Miller plots. $\quad$. $\quad 43$

4.18: A spatially accurate map of every tree in the Balch plot, color-coded by species. $\quad . \quad$. $\quad . \quad$.

4.19: A spatially accurate map of every tree in the Miller plot, color-coded by

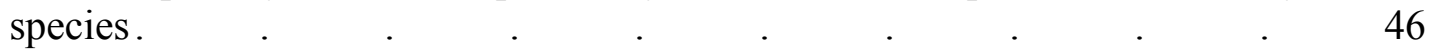

4.20: A spatially accurate map of every tree in the Miller plot, color-coded by species and represented with variable sized points corresponding to dbh class

4.21: A spatially accurate map of every tree in the Miller plot, color-coded by species and represented with variable sized points corresponding to dbh class

4.22: A spatially accurate map of every tree in the Balch plot with an unmanaged

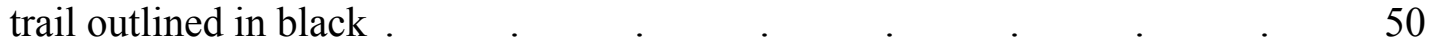

4.23: Semivariogram curves for all dbh data from Balch $\quad$. $\quad . \quad$. $\quad 52$

4.24: Semivariogram curves for all dbh data from Miller $\quad$. $\quad$. $\quad$. $\quad 52$ 


\section{CHAPTER 1: INTRODUCTION}

Historical and present-day land uses can influence the composition and spatial patterning of forest stands (Foster \& Aber 2004, Scheller \& Mladenoff 2002, Zhou et al. 2011). Although harvesting strategies, land use changes, and natural disturbances are known to shape forest composition, the mechanisms that drive change and the patterns that emerge are still poorly understood (Scheller \& Mladenoff 2002, Zhou et al. 2011). Urban forests, in particular, are receiving increased attention as systems that provide many ecological services, but experience increasing impacts. In the past, research on the urban forest has typically focused on street trees and municipal parks. However, Portland, Oregon has a unique resource within its city limits. Comprised of over 5,100 acres, Forest Park is one of the largest forested natural areas within city limits in the U.S. (Portland Parks \& Recreation 2010).

As part of a long-term investigation into the ecological status and progression of Forest Park, this study examines baseline data collected from two permanent plots established in the summer of 2010. The exploration investigates data for emergent stand composition and spatial patterns, and uses historical reference conditions to create an initial picture of the 2010 long-term ecological research sites. As an initial step, this study begins to explore questions regarding the ecological status of Forest Park and how land use and disturbance, past and present, may shape Portland's forested reserve.

\section{Project Overview and Direction}

The drive to begin long-term ecological research into the condition and changes occurring in Forest Park was fueled by several ecological and management 
questions. Most prominently, a study done by Nancy Broshot in the early 1990's found a significant effect of urbanization on stand structure in the park (2007). Findings from her study also evidenced a lack of tree species recruitment throughout the park and additional research has exposed possible broad scale tree mortality (Broshot, personal communication, February 2010). Broshot's study prompted questions regarding the cause of tree mortality and lack of seedling recruitment, in addition to questions on how urban impacts can be minimized in Forest Park.

The urban influence on Forest Park has also inspired numerous questions that appeal to management decisions and ecological status issues within the park. The consequences of the urban heat island, and the impacts from diverse recreational uses in Forest Park, spawned questions regarding the human thumbprint on park ecology. Initial proposed questions have included: what is the effect of increased urban temperatures on plant health? What are the implications of mountain biking, off trail hiking, and other recreational uses on soil compaction and non-native species invasions? What are the other urban influences on the park and how can they be mitigated to help achieve a more pristine condition? The future of the park in the face of climate change is also an uncertainty that begs investigation. Since the park abuts Portland's urban center and experiences increased urban temperatures and atmospheric pollution, is it possible to observe Forest Park as a model for western temperate forest processes under climate change?

Finally, the role of Forest Park in the larger ecological context has also motivated this project. The connectivity of the park to the coastal range and the potential for the park to become an island as urban areas expand, are thought 
provoking concepts. The parks convenient proximity to the urban center, and consequently numerous educational facilities, has sparked an interest in how the park can be used for ecological education and the cultivation of stewardship attitudes. Unquestionably, Forest Park is of great value to those who live in and near Portland Oregon, and this investigation takes one initial step at addressing the umbrella question: What is the ecological status of Forest Park and what changes are expected as time progresses?

In order to establish a means for beginning to answer the multitude of questions surrounding the park, a first set of permanent plots were established in June of 2010. In the summer of 2011, a second set of plots was installed in old growth sections within and near the park. A profusion of data was collected in each plot, with the plan to re-sample these sites in ten-year increments. As a first step into the longterm look at Forest Park, this study is intended to provide a look at tree growth and spatial patterning in the initial Forest Park permanent plots and examine stand composition and condition in the two initial sites.

\section{Research in Forest Park}

Several studies have been conducted specifically within Forest Park, or have included the natural area, to explore various ecological themes. In 1982, Marcy Houle explored the major relationships that occur between the vegetation, bird, and mammal species residing in the park. Her study determined which species of breeding birds and mammals inhabited the park, as well as classified vegetation types (Houle 1982). In 2009, The U.S. Fish and Wildlife Service funded a broader study on terrestrial vertebrate diversity within and among Portland's parks and green-spaces (Portland 
State University 2010). The most extensive analysis of the Northern Pygmy-owl, Glaucidium gnoma, is also occurring within Forest Park. Life history, breeding biology, and habitat selection have been thoroughly investigated over a several year study (Deshler 2010). In addition, Portland State University currently conducts aquatic macroinvertebrate monitoring and terrestrial mollusk surveys (Portland State University 2010).

Vegetational research has occurred in Forest Park, including studies on invasive Hedera helix, leaf litter decomposition, and the relationship between urbanization and stand dynamics. Eppley and Dobberstein are exploring environmental impacts of $H$. helix during the height of invasions and after targeted control efforts in the park (Portland State University 2010). In 2009, Dresner and Moldenke compared leaf litter decomposition rates between Forest Park and the H. J. Andrews. A follow up study is in the works to explore the role of shredder populations on leaf decomposition (Portland State University 2010). Finally, Broshot's 2009 study on forest stand dynamics in Forest Park is a major contribution to long-term research in the park.

The purpose of the Broshot (2009) study was to determine whether there were changes in stand characteristics in a natural forested area along an urban-rural land use gradient. Using Forest Park as the study site, she hypothesized that the more urban sites would have different stand characteristics, i.e. changes in tree density and recruitment, as compared to more rural sites. Results indicated that tree species richness and diversity were greater in the far section of the park than in those closer to the city. Tree density was significantly greater in more rural sections, as was shade- 
tolerant sapling density. Thuja plicata and Tsuga heterophylla were more dominant in far sites than in the city or middle sections of the park and T. plicata had significantly larger diameters at breast height $(\mathrm{dbh})$ in the far end of park than in the other sections. However, Acer macrophyllum and Pseudotsuga menziesii had a larger mean dbh in the city section than in the middle. Finally, trees in the city section were significantly older than those in the far or middle parts of the park (Broshot 2009). Broshot concluded that urbanization appears to be affecting stand structure in Forest Park.

\section{Impacts to the Urban Forest}

Unquestionably, Forest Park is an urban forest, as it is located within Portland's city limits. However, due to its size and how it is managed, the park is maintained as a large natural forest. While urban forestry research most commonly investigates street trees and smaller municipal parks, issues pertaining to these types of forests concern Forest Park as well. Diversified recreational activities are present in all parts of Forest Park. The forest experiences a high volume of human traffic, including equine and mountain bike use (Portland Parks \& Recreation 2010). Development occurs up to the edge of the park in all but the most northern sections and since it abuts downtown Portland, it is suspected to be influenced by urban atmospheric and temperature effects. Consequently, considering the many influences that impact the urban forest is essential to interpreting processes that occur in Forest Park.

\section{Atmospheric Influences in the Urban Forest}

The urban forest often experiences a unique set of influences, in addition to those experienced by natural forested systems. Atmospheric outputs, such as $\mathrm{CO}_{2}$ and $\mathrm{CH}_{4}$, are closely tied to urban areas and can influence uptake and physiological 
responses in vegetation (Bazzaz 1990, Groffman \& Pouyat 2009). Increased temperatures associated with urban areas can also influence tree growth dynamics and the land-atmosphere energy exchange (Ormond et al. 1999, Apple et al. 2000).

The relationship between the urban forest and the land-atmosphere energy exchange is of great interest in an increasingly urbanizing world. As of 2003, tree canopy cover in urban areas averaged about 27\% (Dwyer et al. 2003). Consequently, the urban forest has been investigated as a contributor to carbon uptake and thus, a potential carbon sink (Groffman \& Pouyat 2009, Pataki et al. 2006). While Groffman \& Pouyat (2009) found rates of $\mathrm{CH}_{4}$ uptake to be much lower in urban forests than in natural ones, the potential for Forest Park, a natural forest in an urban location, is intriguing. Urban trees may also reduce atmospheric $\mathrm{CO}_{2}$ though direct $\mathrm{CO}_{2}$ sequestration. But, indirect reduction has also been observed by reducing incident radiation through shading effects, altered wind patterns, and increased evaporative cooling (Escobedo \& Nowak 2010, Pataki et al. 2006).

\section{Heightened Traffic and the Soil Profile in the Urban Forest}

As a city park, Forest Park experiences a substantial amount of traffic via diversified recreational use. Human traffic, including biking, horseback riding, and abundant pet traffic, is linked to increased soil compaction which may have a number of ecological consequences (Craul 1994, Ruiz \& Carlton 2003). Compaction can alter soil structure by increasing soil bulk density, particularly by breaking down soil aggregates, which decreases porosity, aeration, and infiltration (Kozlowski 1999). Consequently, compacted soils change hydrology by increasing water runoff and soil erosion. Soil compaction can also impede root penetration, reduce soil oxygen, and 
diminish soil water concentrations causing physiological dysfunctions in plants (Craul 1994, Kozlowski 1999, Quigley 2002).

Forest trees have exhibited reduced growth and death when soil water and oxygen is low. Reduced water absorption can cause leaf water deficits and poorly aerated soils reduce height, leaf, cambial, and reproductive growth in trees (Kozlowski 1986). Soil compaction has also been observed to induce changes in growth hormone balances in plants, especially increases in abscisic acid and ethylene (Kozlowski 1999). Mineral absorption by plants can be minimized in compacted soils and photosynthetic rates may be reduced as a result of smaller leaf areas. Kozlowski (1999) also explains "severe soil compaction adversely influences regeneration of forest stands by inhibiting seed germination and growth of seedlings, and by inducing seedling mortality." As a highly trafficked urban park, Forest Park is likely experiencing soil compaction in varying degrees within its boundaries.

\section{Invasive Species in Forested Systems}

Invasive species compete with native vegetation and can reduce growth and regeneration of trees, which can be a major factor in urban forest sustainability (Vitousek et al. 1997, Ruiz \& Carlton, eds. 2003). Moreover, humans frequently act as vectors for invasive species, and traffic through an area can facilitate their spread further into a natural system (Ruiz \& Carlton 2003). Invasive species can outcompete native species and modify habitats, while being very difficult to control. In some cases, invasive species cause extinction, by directly killing another species or by indirectly outcompeting them (Boersma \& Van Buren, eds. 2006). In Forest Park, thirty non-native invasive species are listed as primary concerns and include Hedera 
helix, Ilex aquifolium, Prunus laurocerasus, and Sorbus aucuparia, all of which are found in the Balch permanent plot (Forest Park Ivy Removal Project 2008).

Non-native invasive species (NIS) can affect plant community structure in a number of ways. I. aquifolium colonizes forest gaps and can shade out other understory species with its dense evergreen canopy (Boersma \& Van Buren, eds. 2006). H. helix can form "ivy deserts," or patches of continuous cover, that can exclude other understory species, choke out overstory trees, and prevent regeneration of woody plants (Boersma, \& Van Buren, eds. 2006, Dlugosch 2005). Invasive species compete for light, soil moisture, and nutrients and often have growth strategies that facilitate rapid spread (Schwartz et al. 1996). By reducing biodiversity and affecting ecosystem structure, invasive species can change the composition and dynamics of forested ecosystems (Schwartz et al. 1996, Boersma \& Van Buren). With the diverse physical, biological, and social services that the urban forest provides, it is crucial that it continues to be examined to more fully understand how to protect and manage it.

Addressing the impacts and processes related to the urban setting of Forest Park is important to this investigation. However, the expansive park is managed as a natural forest. Consequently, it is important to explore the characteristics of temperate forests in the Pacific Northwest, which give insight into the natural ecological processes that may be occurring in the park.

\section{Research in Western Temperate Forests}

Forest ecology in the Pacific Northwest is a widely researched subject matter. Considering the importance of timber and other forest resources, along with the vital ecosystem services that PNW forests provide, it is no surprise that there is a desire to 
understand and responsibly manage the regions forested landscapes. Research now recognizes substantial diversity in the processes and structures that occur within Pacific Northwest forests. Consequently, studies continue to explore how they grow, naturally and under diverse management strategies. Compositional characteristics are an important piece to understanding the ecology and structures of forest stands and help classify a stand to be in its early, mature or older successional stages.

\section{Structural Composition \& Succession in Western Temperate Forests}

Succession in western temperate forests is a continuous process, and cannot be delineated into discrete stages (Franklin et al. 2002). However, stands do tend to have certain structural and compositional components at different ages. Typically, tree density and mean stand diameter at breast height ( $\mathrm{dbh})$ are important aspects in discriminating between age-classes (Spies \& Franklin 1991, Tappeiner et al. 1997). Tree density is commonly found to be higher, sometimes double, in young-growth forests as it is in mature and old growth forests (Bailey 1996, Spies and Franklin 1991, Tappeiner et al. 1997). Mean dbh is more variable, but can peak in mature stands, where smaller, shade-tolerant trees are not as abundant as they are in old-growth sections (Spies and Franklin 1991). Shade tolerant saplings are often most abundant in old growth stands, where shade-intolerant species are less capable competitors (Spies \& Franklin 1991).

As scientists have explored the variable characteristics that distinguish stand age, density of shade-tolerant overstory trees and debris variables are most notable. Discernibly, the density of large-diameter shade tolerant trees increases dramatically with age in western temperate forests. However, in addition to the living trees, size 
and decay class of debris is fundamental to stand composition. The volume and size of snags increases dramatically with age in a stand (Spies and Franklin 1991, Franklin et al. 2002). While small snags and logs may be more numerous in young stands, they are often decayed in mature stands. Consequently, snag volume tends to be lowest in mature stands and it is not until a stand reaches old growth conditions that coarse woody debris abundance peaks (Spies \& Franklin 1991, Franklin et al. 2002).

The spatial arrangement of trees and foliage within the stand also change as a stand ages. In young stands, tree foliage is generally concentrated high up in the canopy with little in the lower parts. Conversely, old-growth stands often have live branches continuously distributed from the ground up to the top (Franklin et al. 2002). Spatial patterns of trees, including fallen snags and logs, also become more complex as a stand ages. As disturbance creates canopy gaps, spatial heterogeneity increases and the forest becomes a mosaic of developmental phases (Franklin et al. 2002). Although it is important to consider the continuity of successional processes within a stand, research has tried to classify developmental stages for western temperate forests.

Franklin et al. (2002) complied several classification schemes in order to determine nine exemplary developmental stages in western temperate succession. The first considers disturbance and legacy creation.

1. Disturbance and legacy creation: Stand development begins with an event that allows for the establishment of a new dominate tree cohort. Natural disturbance events rarely fully eliminate structural components of the previous stand, and biological legacies (persisting live and dead structures) generally remain. However, in the case of 
clear-cut timber harvest, few legacies are left and organic soil matter is often removed. Disturbances vary in intensity, size, frequency, and homogeneity, but once space is made for new cohort establishment, stand development begins (Franklin et al. 2002).

2. Cohort establishment stage: New cohort establishment varies in duration and stand density. Stocking levels can be influenced by a lack of a seed source, such as following intense wildfire or when the stand is distant from seed trees. If stocking levels are high in a relatively short period of time, canopy closure often results in a period of intense self-thinning. However, if a stand undergoes gradual canopy closure, self-thinning is minimized (Franklin et al. 2002).

3. Canopy closure stage: Somewhat of a transitional stage between cohort establishment and competitive exclusion, this stage can be a dramatic developmental period for stand structure. Environmental conditions in the understory change as light levels, wind, and temperature are reduced. Some species of lichen, shrubs, and herbs are repressed as others increase. Since canopy closure is dependent on density and productivity of the cohort, the stage may take several decades, or may never fully occur (Tappeiner et al. 1997, Franklin et al. 2002).

4. Competitive exclusion stage: As an extended period of development in a young stand, the growing tree cohort dominates this stage. Characterized by rapid growth and biomass accumulation, competitive exclusion is strong during this stage and competition among young trees may cause substantial self-thinning. Lower branches of trees are often pruned and crown-class becomes differentiated. In Douglas-fir forests, this stage usually extends from canopy closure to 80 to 100 years. 
5. Maturation stage: Pioneer trees reach their maximum height during the maturation stage. Coarse woody debris is at minimal levels and there is a shift from densitydependent to density-independent causes of overstory mortality. Understory reestablishment occurs as canopy gaps were created during competitive exclusion, allowing more light to reach the forest floor. Although it is highly variable depending on seed source and conditions, significant shade-tolerant species establish during maturation (Tsuga heterophylla and Thuja plicata). Typically beginning around 80 to 100 years of stand age, the stage may persist for 100 to 150 years in naturally regenerated forests (Franklin et al. 2002).

6. Vertical diversification stage: Development of late-succession and old growth attributes occur during vertical diversification. Canopy continuity between the crown and the ground develops when shade-tolerant species grow into co-dominant canopy positions. As decadence of overstory trees increases, coarse woody debris continues to build and foliose lichen communities grow. In Douglas-fir stands, this stage occurs at 250 to 300 years old (Franklin et al. 2002).

7. Horizontal diversification stage: Gap creation and expansion over time allow for stands to evolve into a mosaic of structure units. In Douglas-fir forests this stage begins after about 300 years and is dominated by a continuation of gap development. Shade-tolerant species in the upper canopy control light levels below, instead of remaining Pseudotsuga menziesii. Density of the pioneer P. menziesii cohort continues to decline (Franklin et al. 2002).

8. Pioneer cohort loss stage: Shade-intolerant species are still present but canopy gaps are too small for successful regeneration. Dominant living P. menziesii are lost and the 
debris and gaps created is consequential for ecosystem processes and nutrient cycling. Since P. menziesii are a long-lived species, this stage occurs between 800 and 1300 years of stand age (Franklin et al. 2002).

9. Structural "endpoint" of stand development: When a stand is horizontally and vertically diverse, with a mixture of shade-intolerant and shade-tolerant species, the stand is considered old growth. Spatial patterning is heterogeneous and light to moderate disturbance creates a mosaic of structural units. In western temperate forests, T. heterophylla and T. plicata are old-growth species (Spies and Franklin 1991, Franklin et al. 2002).

A lot of research has been done in order to categorize successional stages in forest stands and the research explicates that disturbances like timber harvest, impact stand structure and composition.

\section{Logging in Western Oregon - Impacts on Stand Composition and Condition}

Timber harvest is one of the most prevalent disturbances in the western temperate forest. Millions of board feet are harvested in Washington and Oregon every year and the industry provides a considerable amount of employment and state revenue (Washington State DNR 2009). Historically, much of Forest Park was felled for timber production. Research on the impacts of logging on forested systems has increased in the last several decades, and information concerning far-reaching ecological implications has emerged. In addition, the exploration of how stands regenerate without having been harvested, naturally after a harvest, and after replantings, is of great interest to how Forest Park may evolve after a history of logging. 
The ecological implications of logging, particularly clear-cutting harvest methods, can affect soil productivity, hydrological cycles, sedimentation, regeneration, and vegetation composition (Swanson \& Franklin 1992, Waston et al. 2000). Biological diversity in managed forests is often reduced and ecological invasions are presenting new threats to forest re-establishment (Halpern \& Spies 1995). Several studies have also explored how second generation stands are re-establishing, either naturally, or via replanting methods, and how they compare to old-growth conditions. Much research has taken place in the Oregon Coastal Range, where Forest Park is closely located.

Forested systems allowed to regenerate naturally after logging disturbance have distinct differences from unlogged stands. Winter et al. (2002) found that trees in unlogged old-growth stands in the Oregon Coastal Range regenerated at much wider spacing than did trees in nearby naturally regenerated clear-cut stands. The closer spacing between regenerated trees was linked to reduced diameter growth, short crowns, and structurally simple live branches, confined to the upper one-third of the bole. The structural difference is compounded in replanted stands, where sites are stocked with a single species at around 600 trees per hectare (Tappeiner et al 1997). Reduced diameter growth and top-heavy crowns can cause trees to buckle and break when they become tall (Winter et al. 2002). Reduced spacing between trees also contributes to growth rates differences among unlogged and naturally regenerated stands.

The density of trees in unlogged stands is often much less than that of regenerated logged stands (Tappeiner et al. 1997). In the Oregon Coastal Range, some 
stand densities were found to be upwards of 1000 trees per hectare in 30-50 year old naturally regenerated stands. Although self-thinning reduced densities by about $50 \%$ after 30 years, substantial inter-tree competition was illustrated by rapid and consistent diameter growth decreases in sampled trees (Tappeiner et al. 1997). A study by Tappeiner et al. (1997) noted that in unlogged stands, the average annual growth rate for $P$. menziesii was roughly .5 centimeters per annum, which was significantly higher than in regenerated stands. Even when land management includes silvicultural practices to thin regenerated stands, growth and structural differences occur.

In the Oregon Coastal Range, Tappeiner et al. (1997) found that neither natural nor prescribed thinning of managed stands had reduced the density of trees below that of older, unlogged stands. In all sampled sites, the density of young stands was greater than 55 trees per hectare, which is the density at which reduced diameter growth and self-thinning are likely to occur. They concluded that, "today's young-growth stands that regenerated after logging are developing at much higher densities than during development of old-growth Douglas-fir stands. Further, tree establishment in the old stands typically occurred over long periods of time...[with] little inter-tree competition," (Tappeiner et al. 1997). Consequently, stand competition and condition in forests after logging appears to be different than historical stand evolution in the western hemlock zone, even with silvicultural thinning.

Since western temperate forests span great distances, and incur diverse landuse and disturbance histories, one area of study that is very promising for forestry analysis is landscape ecology. 


\section{Using Spatial Analysis}

Landscape ecology principles and tools provide effective means for exploring the broad spatial and temporal changes occurring in western temperate forests. Landscape ecology emphasizes the diverse ecological influences and broad spatial scales that affect patterning in ecosystems (Turner 1989). By considering developmental dynamics that create heterogeneous patches, the interactions between heterogeneous landscapes, and the management of those diverse areas, the landscape ecology lens is fundamental to exploring western temperate forests (Turner 1989). Although this study does not use satellite imagery, landscape ecology principals are important to consider as the long-term look of Forest Park moves forward. Already mapping and monitoring disturbance in the western temperate region has yielded some interesting results

In 2002, Cohen et al. examined over 4.6 million forested hectares in the Pacific Northwest, for landscape changes between 1972 and 1995. Using satellite imagery to map and track landscape patches over 23 years, Cohen et al. found the Coastal Range of Western Oregon to be the most disturbed forested landscape in the region.

Observing timber harvest to be the most dominant disturbance, researchers were able to compare logging across different land ownership types. The analysis was also able to compare logging disturbance with other major disturbances over time, including fire. Coupling fire history with their findings, the analysis was able to deduce that the Cascade Range was a harvest-dominated system with 426 times the amount of harvested area as burned area. Using the landscape ecology lens to analyze spatially 
and temporally heterogeneous patterns is important to looking at forest landscape change in urbanizing areas as well.

A 2011 study done by Zhou et al. was able to characterize the spatial-temporal dynamics of forest cover changes from 1914-2004 in an urbanizing part of Maryland. The study was able to address forest change dynamics that may not have otherwise been apparent from a ground-based, sampling study. They found that although forest cover remained about the same over the 90 -year period, forest patch size decreased while the amount of edge increased. The study also found that forest cover tended to be more stable closer to the urban center because further away, development was still occurring (Zhou et al. 2011). Consequently, the study emphasized the importance of looking at patch heterogeneity and change, instead of just a total forest cover analysis.

Aside from broad-scale satellite analyses, landscape ecology also provides essential tools for exploring data on the ground sampling level. Using a spatial point pattern analysis or a measure of variance within a forest stand can elucidate patterns in stand composition that may otherwise go unnoticed. Landscape ecology also gives great weight to spatial and temporal scales, and applying historical ecology to modern analyses. Considering long time sequences is highly relevant to systems with longlived organisms, like trees (Swetnam \& Betancourt 1999). All in all, the landscape ecology lens provides great tools and insight for in depth looks at forest stand composition and condition.

Considering the spatial and temporal scales at work in Forest Park, it is important to explore the ecological and land use history of the region known as the Tualatin Mountain Range. 


\section{CHAPTER 2: ECOLOGICAL AND LAND USE HISTORY IN FOREST PARK}

Figure 2.1 Overview map of Forest Park, Portland, Oregon - 2011

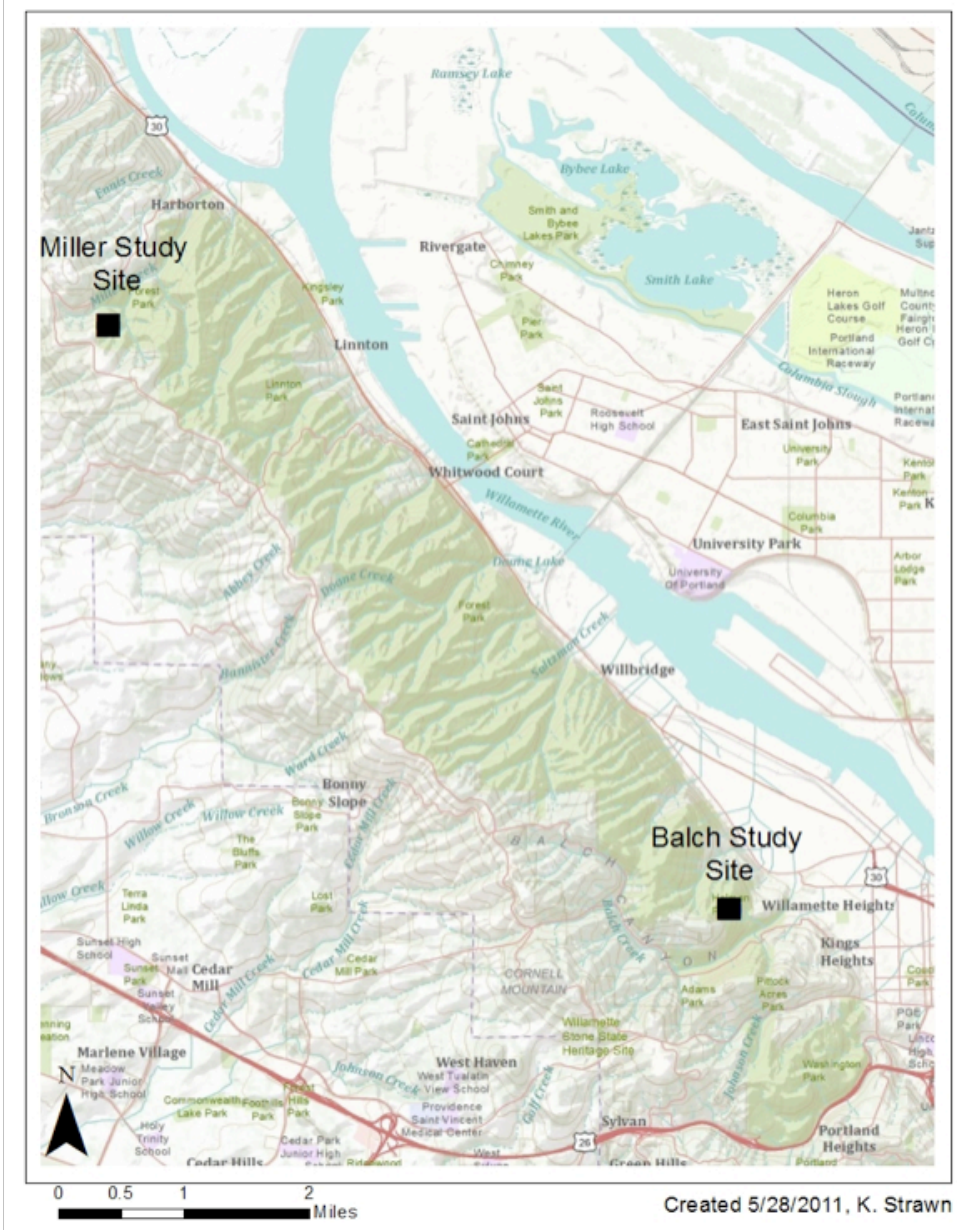

The Early Years (Pre- and Early Settlement History)

Although Native Americans have inhabited the Pacific Northwest for around 10,000 years, written description of the area that is now Forest Park does not begin until the arrival of Europeans. Nonetheless, the journals of Lewis and Clark help surmise that Forest Park shared similar historical conditions to much of the Western Hemlock zone. In 1806, Captain William Clark and some of his expedition party are believed to have camped in the area that is now occupied by the University of 
Portland. In one journal entry, Captain Clark describes what he saw while looking at the hills that would eventually be Forest Park: "The timber on them is abundant and consists almost exclusively of the several species of fir already described [Douglas-fir, grand fir, and western hemlock], and some of which grow to a great height," (De Voto 1953). Nevertheless, as European settlement increased, the face of the Tualatin Mountain Range, future home of Forest Park, changed dramatically.

\section{Post-settlement Land Use and The Creation of Forest Park}

In the 1840 's early pioneers developed trails that traversed the Tualatin Mountain Range, to facilitate wheat and produce delivery across the steep terrain (Kuhn 2005). Between 1845 and 1849 the trails were widened and improved and eventually the paths became the foundations for Cornell, Germantown, and Newberry Roads. During this time the U.S. government owned the land, but by 1855 the area was almost entirely deeded to settlers. However, as homestead development expanded on the level lowlands, the steep slopes of the Tualatin Mountains were difficult to build on and were left for logging (Munger 1960).

\section{Logging, Fire, and Construction Disturbance in Forest Park}

By 1860 , most of the big trees that comprised the virgin forests of Forest Park were removed (Munger 1960). Clear-cutting was the preferred method of timber harvest and the hills of Forest Park were not exempt from the creation of "Stumptown." Slash burns followed most clear-cuttings, to clear brush (Broshot 2007). In 1889, the first recorded large-scale fire that burned in the area occurred. The fire broke out between Barnes and Cornell Road, and burned roughly 400 acres of the 
Figure 2.2. Map of the area burned in the 1889 fire - created by David Kuhn

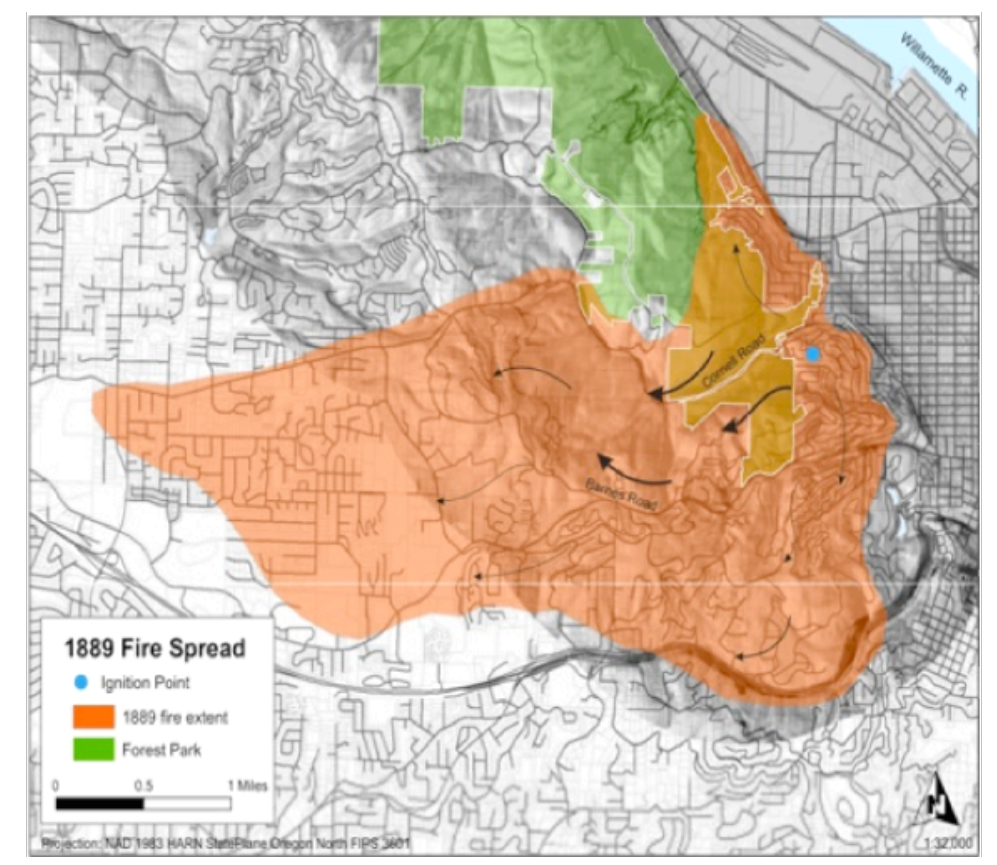

southern tip of modern-day Forest Park (Kuhn 2005). Referencing an 1889 article in the Oregonian, that described the fire; David Kuhn created a map that estimates the burned area within and outside of the current park boundaries (Figure 2.1).

In 1889, the Municipal Park Commission for Portland was created and the founder, Reverend Thomas Eliot, requested a visit from the notable landscape architects, John Charles Olmsted and Frederick Law Olmsted Jr. (Houle, 1996, Kuhn 2005). In 1903, the Olmsted brothers obliged and after touring the area, submitted a park plan to the Commission in December. However, despite the Olmsted brothers' proposal, it would still be some years before the park was established.

In 1910, the city of Linnton was incorporated at the bottom of the Tualatin ridge, with its city limits including most of the future park area (Munger 1960). Logging continued into 1914, with the establishment of wood cutting camps to 
alleviate unemployment. Old logging trails, stumps, and wooden discs still remaining in the area also evidence high-grade logging occurring around this time (Fred Nilsen, personal communication, March 2011). By 1915, most of the land within the park was parceled for development and a scenic Hillside drive, connecting Germantown Road to Thurman Street in Portland, was proposed.

Between 1914 and 1915, Hillside Drive was quickly graded, but cost nearly twice the expected amount (Munger 1960). Portland annexed Linnton in 1915, and in order to pay for the huge cost of the road, each subdivision lot was assessed a fee. However, most of the fees were never paid and eventually all the lots were foreclosed on. That winter, landslides came down on Hillside Drive, increasing the cost of maintenance, which allowed it to fall into disrepair. In 1933, a city ordinance, sponsored by the Sons of Norway, renamed Hillside Drive into Leif Erickson Drive.

Woodcutting camps continued in the area through 1937 and another major fire burned in 1940. The ignition point of the 1940 Bonny Slope fire is unknown, but the two-day fire burned over 1,000 acres in the Tualatin Mountains. Most of the area burned falls outside of modern day Forest Park boundaries, but after the fire, tall dead snags and sparse cover remained in the burn zone. A subsequent fire protection plan described the area as having the second most hazardous fuel type, after logging slash. The report deemed Bonny Slope as an area that would be difficult to control and have a high rate of spread if fire broke out again (Kuhn 2005). Kuhn (2005) created a map of the 1940 Bonny Slope fire, with estimated burn areas within and outside of the Forest Park boundaries (Figure 2.2). 
Figure 2.3. Map of the area burned in the 1940 fire - created by David Kuhn

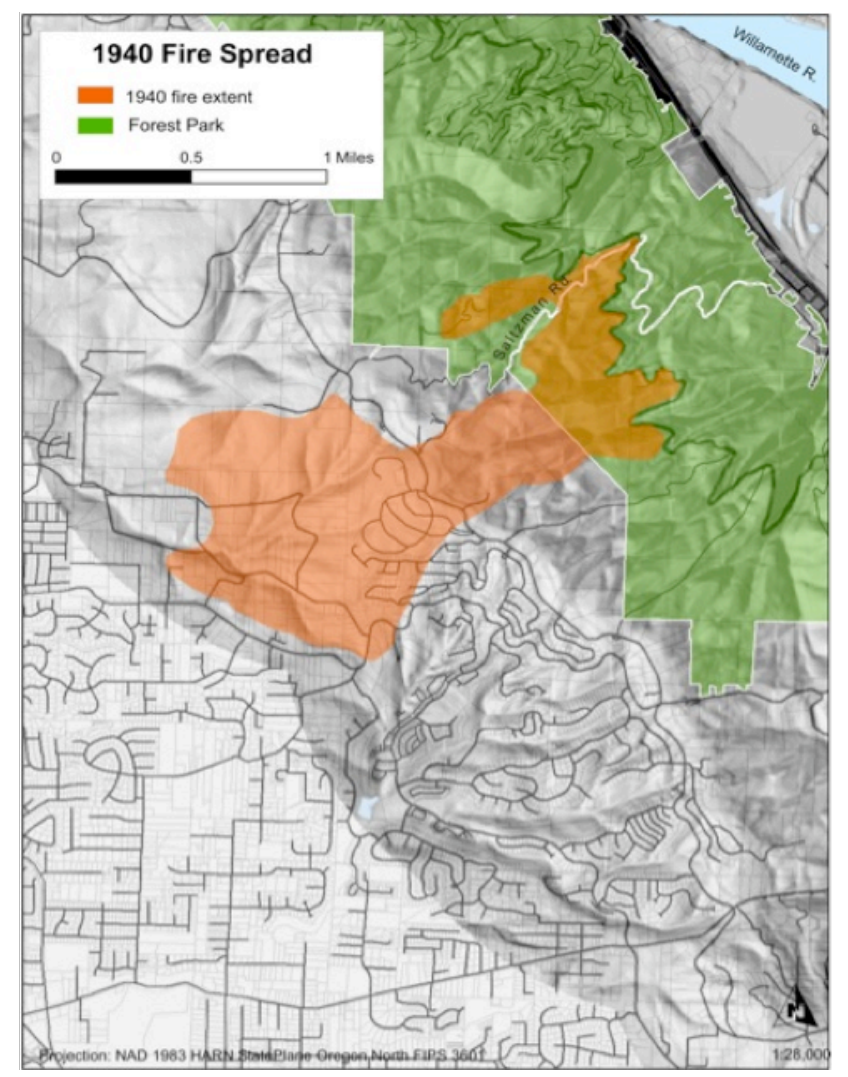

It was not until 1944, that the City Club formed a committee of five representatives to address park status in the northwest hills (Munger 1960). In 1946, a permanent "Committee of Fifty" was formed and by June 1947, the committee recommended that the city dedicate all city-owned lands in the Tualatin Mountains for a park (Munger 1960). After unanimously accepting the Committee and Planning Commission plans at a public hearing in July of 1947, the task of land consolidation and transfer to the park bureau began. On September 25, 1948, Forest Park was formally dedicated (Munger 1960). 


\section{Forest Park - 1948 to Present}

After the formal dedication of the park, the area within the original exterior boundary was estimated at 6,168 acres (2,496 hectares). However, due to extensive privately owned holdings, only 4,200 acres (1,700 hectares) actually belonged to the park bureau (Munger 1960). Over the years the city of Portland has continued to acquire privately held land adjacent to and within the original park boundary.

Figure 2.4

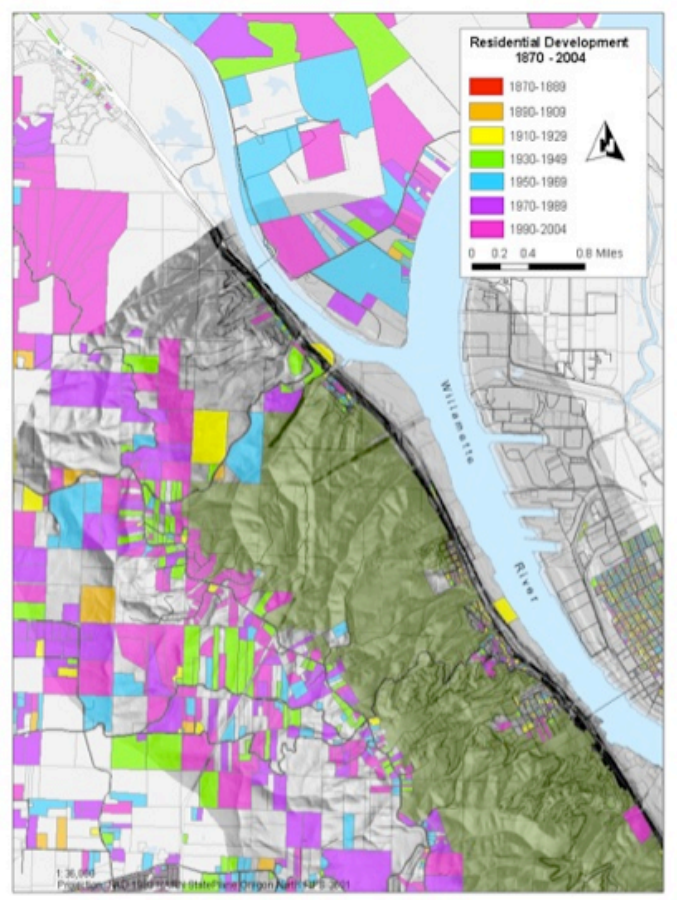

Figure 2.5

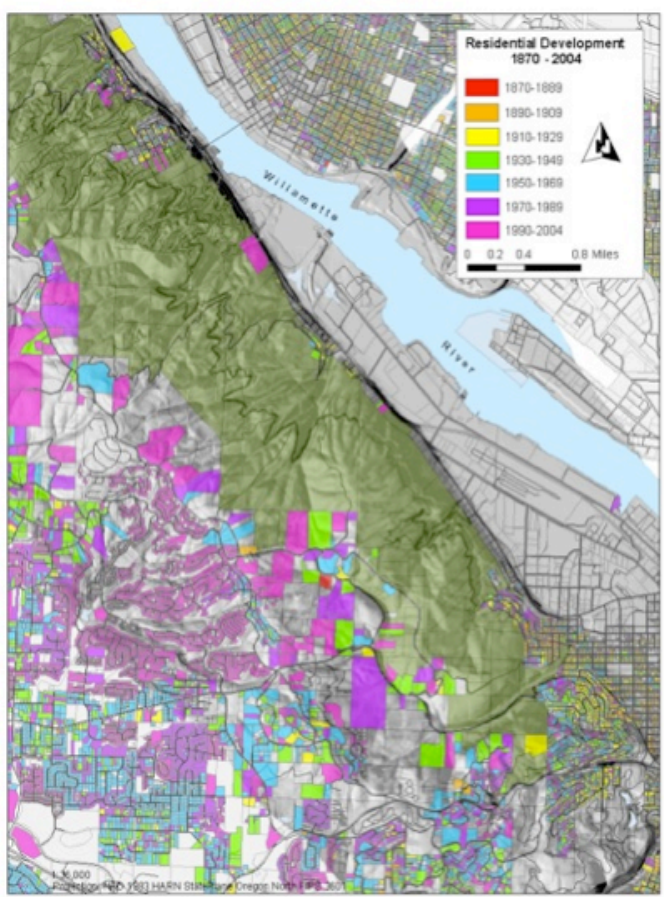

Figure 2.4 and Figure 2.5. The residential development within and surrounding Forest Park from 1870 to 2004 - created by David Kuhn

However, development has continued right up to the park boundary since its dedication. In 2004, a map of the residential development over the course of $\sim 134$ years was created by David Kuhn (Figure 2.3 \& Figure 2.4). Now the park encompasses 5,167 acres, but ecological disturbances within the park boundaries continue to shape the landscape (Forest Park Conservancy 2011). 
Since the formal creation of Forest Park, the largest documented fire to date has occurred within its boundaries. In 1951, a maintenance crew working near Leif Erickson Drive is believed to have accidentally started a fire that burned from August

Figure 2.6

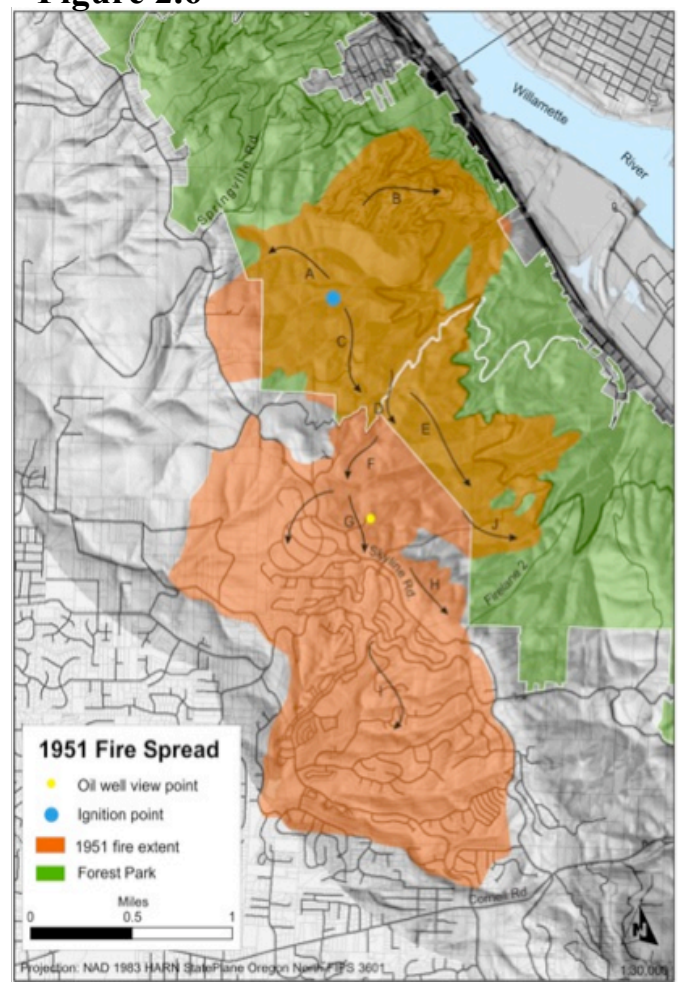

Figure 2.7

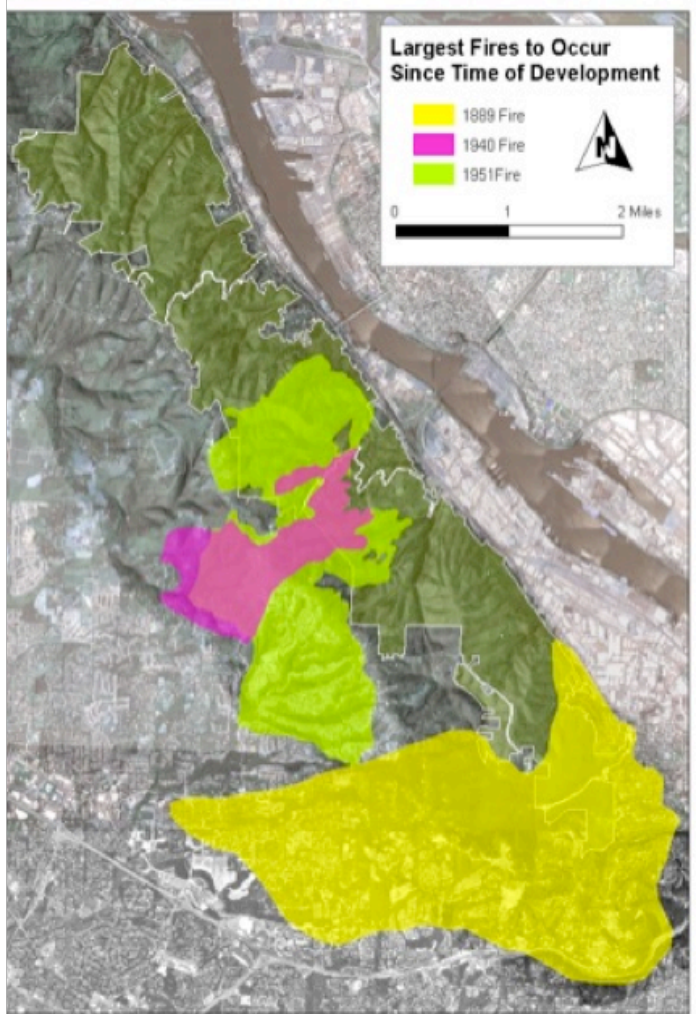

Figure 2.6. Map of the burned area in the 1951 fire - created by David Kuhn

Figure 2.7. Map of the three major fires to occur in Forest Park since 1850

$18^{\text {th }}$ to August $22^{\text {nd }}$ (Kuhn 2005). The fire burned nearly 2,200 acres, about 900 of which were within the park boundaries. The particularly dry summer, north-northeast prevailing winds, and the hazardous fuel type in the Bonny Slope area, facilitated the stand replacing burn. The 1951 fire is believed to have over-burned the majority of the 1940 fire area as well. Again, Kuhn created a map that illustrates the estimated burned area of the 1951 fire (Figure 2.5) and a map that overlay all three major fire events in 
the park (Figure 2.6). Since the 1951 fire, there have not been any obvious major ecological disturbance events.

\section{Invasive Species in Forest Park}

In an interview with Fred Nilsen (2010), a long time city parks manager, he identified biological invasions as a leading threat to Forest Park. The poster child for the invasion problem is Hedera helix, or English Ivy (City Club of Portland 2010). In a 2005 report by the No Ivy League, the primary organization combating NIS removal in the park, the Balch Creek watershed was classified as "substantially invaded" by $H$. helix. Edge areas of the park were also categorized as "substantially invaded," while the interior of the park experienced low to moderate encroachment. In addition, Ilex aquifolium (English Holly), Rubus armeniacus (Himalayan Blackberry), and Clematis vitalba were identified as major invaders throughout the park (No Ivy League 2005). Organizations like the No Ivy League and the Forest Park Conservancy do a lot of work to remove the ecologically disruptive species, but non-native invasive species are still abundant in Forest Park, and efforts to control them continue.

The following exploration investigates tree growth, stand composition, and spatial patterns of two permanent plot sites established in 2010. While only one year

of data had been gathered at the time of this analysis, interesting compositional patterns are already apparent. The work done here will contribute to a better understanding of how to manage Forest Park and to the long-term look at western and urban forest ecology. 


\section{CHAPTER 3: METHODS}

\section{Site Description}

Forest park comprises 5,167 acres, located in the northwest section of the Portland metro area (Forest Park Conservancy 2011). The park is long and narrow, extending in a northwesterly direction along the Willamette River. Approximately 11 kilometers in length, the park varies between $.8 \mathrm{~km}$ and $2.4 \mathrm{~km}$ in width, and has steep topography (Broshot 2007). Elevations in the park range between $20 \mathrm{~m}$ and $335 \mathrm{~m}$ above sea level, with slopes greater than $30 \%$ throughout much of the area. The climate in the region is described as maritime, with typically mild temperatures, substantial precipitation in the winters and warm, dry summers (Broshot 2007).

Forest Park is situated in the Tsuga heterophylla vegetation zone, which includes western red cedar (Thuja plicata) and western hemlock (T. heterophylla) as the primary old-growth species (Franklin \& Dyrness 1988, Broshot 2007). However, the dominant conifer species in the park is now Douglas-fir (Pseudotsuga menziesii), while a majority of the park is dominated by Big-leaf Maple (Acer macrophyllum) and Red Alder (Alnus rubra) (Broshot 2009, Deshler 2010).

\section{Study Design and Data Collection}

In order to begin an exploration into the current ecological status and processes occurring in Forest Park, exploratory trips were made to potential permanent plot sites in the fall of 2009 and winter of 2010. After visits with numerous PSU professors, Portland Parks and Recreation staff, and current Forest Park researcher, Dr. Nancy Broshot, two separate sites were selected based on their differing proximities to Portland's urban center. One site is nested in the Balch Creek drainage, a few blocks 
from a busy neighborhood (Figure 3.1). The second site is located in the farthest north portion of the park, along Miller Creek (Figure 3.1). Each site straddles a small seasonal creek and both are assembled with outer edges aligned on a cardinal direction. Both of the plots are situated on north facing slopes.

Figure 3.1. Map of Forest Park with the locations of the Balch and Miller permanent research plots

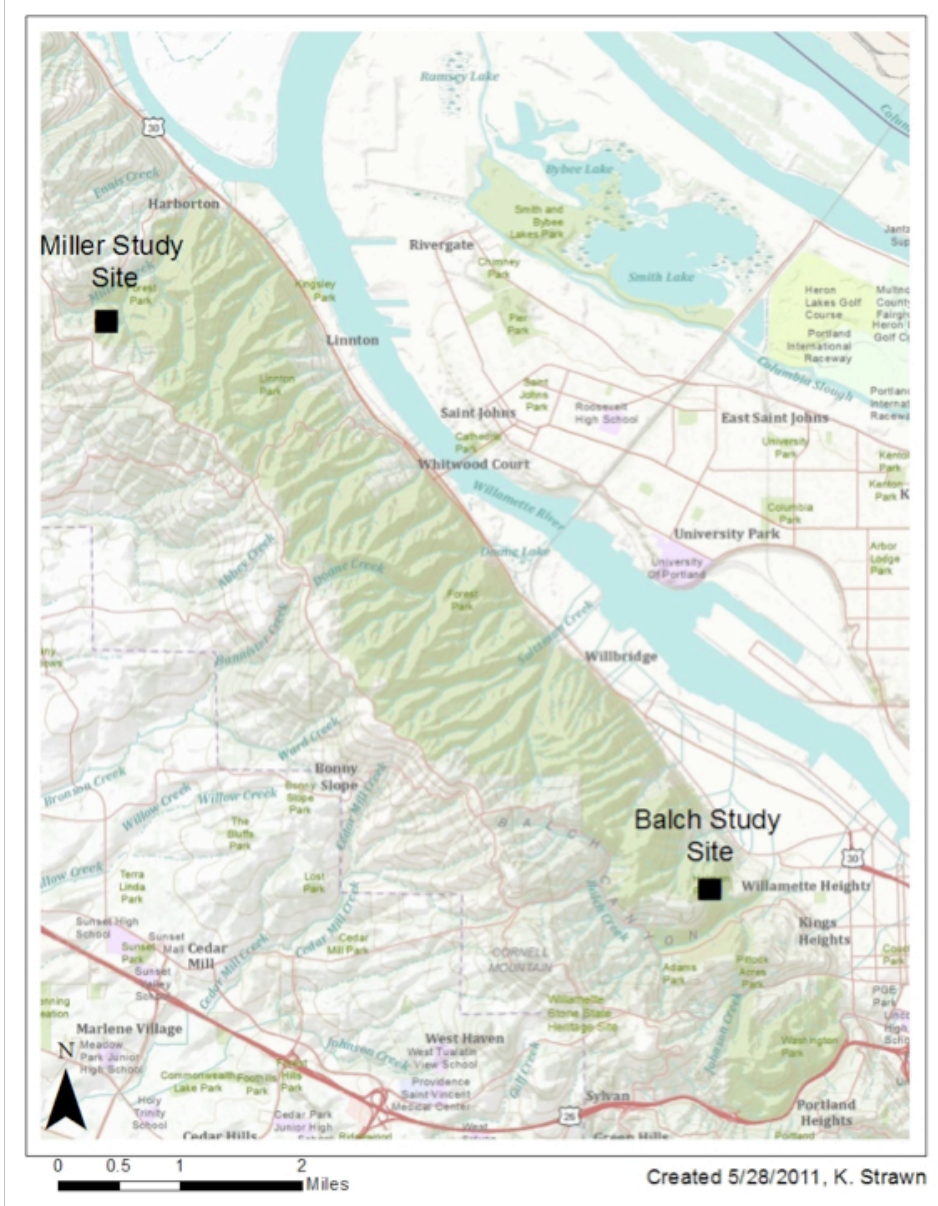

The two permanent plot sites were set up following the USDA Forest

Inventory and Analysis long-term research site protocol. Each plot is 100 meterssquared (a square hectare) and sub-divided into sixteen 25 meters-squared subplots. The subplots were delineated to simplify data collection and facilitate more accurate 
mapping measurements. Within each plot, all trees with a diameter greater than 5 centimeters at breast height (dbh) were tagged and surveyed for dbh, crown class, tree height, crown ratio, lean angle, and tree species. Dbh measurements were obtained using diameter tape and heights were collected with a laser clinometer. A total of 254 trees were surveyed from the Balch Creek site, and 364 were surveyed in the Miller Creek site. Other data collected for each site included vegetation diversity and cover, shrub density and diversity, hobo temperature readings, and surveys of all standing and downed woody debris. In addition, 78 trees were cored at breast height, for ascertaining tree ages throughout the plots.

Since coring and dating all trees in each site was impractical, a size class and species distribution plot was made to select trees to be cored that would represent the breadth of the sites. Twenty-six cores were taken from A. macrophyllum, twenty-six from T. heterophylla, and twenty-sixe from P. menziesii in each site, selected from four size classes. Six to seven cores were taken from each class for each species. The conifers were chosen for tree-ring dating in this investigation because their rings are more easily identified, compared to porous A. macrophyllum. However, 31 cores were taken from A. macrophyllum trees and processed for future use.

All tree cores were mounted to boards and sanded for clarity in reading. Each core was visually dated under a dissecting microscope. Although 24 conifer cores were taken in the Balch site and 23 in Miller, only 19 cores from each plot were of high enough quality to accurately date and use in the analysis. Cores that were missing sections of rings, due to rot or breakage, and cores that did not include the pith, were not used. Since the trees were cored at breast height, their ages are not representative 
of the true ages of the trees, but provide a close estimate. Research on historical land use and disturbance was done via interviews and literature reviews.

\section{Data Analysis}

The open source program $\mathrm{R}$ was used to create scatter plot matrices, with height in relation to diameter for all trees. Once ages were determined, they were also plotted against height and diameter measurements for each cored conifer in the plots. The predominate conifer species (P. menziesii, T. heterophylla, and T. plicata) were parsed out and scatter plot matrices were created for height and diameter values. From the dated cores, tree ages were graphically displayed and an age class distribution graph was created to compare age classes between plots. Dbh histograms were also procured. Mean and median ages for the cored species and for the plot were calculated. Growth rates were determined by dividing dbh by age for each cored tree. Mean growth rates for P. menziesii and T. heterophylla were calculated and compared between sites.

In addition to mean growth rates, mean dbh and mean heights were determined for each species. Mean dbh and mean heights were plotted in bar graphs so the differences could be observed between sites. The mean height and dbh of the predominant tree species (A. macrophyllum, P. menziesii, T. heterophylla, and T. plicata) in each plot were subjected to a two-sample t-test to determine if average tree girth and height were significantly different between the sites.

Before a two-sample t-test was run, diagnostics were checked to test if the data met normal distribution and equal variance assumptions. While tree height data satisfied assumptions, tree dbh data had to be log transformed. T-values for mean $\mathrm{dbh}$ 
and mean height comparisons were procured and significance was determined using a calculated $p$-value $(\propto=0.05)$. Unfortunately, there were not enough $T$. plicata in both sites to be able to meet assumptions and run a t-test for the species.

All trees in the Balch and Miller plots were plotted in ArcMap using the Universal Traverse Mercator grid (UTMs). In addition to a map of each tree location within the plots, a dbh data layer was overlain to create a map of tree girth classes within each site. The tree maps established $x-y$ coordinates for each measured tree, which allowed for a spatial analysis using a semivariogram. A semivariogram is an analysis of spatial correlation and characterizes the continuity of a data set. It is designed to describe spatial relationships, such as in the case of this analysis, where tree dbh between sampled trees was explored for any corollary relation.

\section{Expected Findings from Balch and Miller Plots}

1. Based on initial reviews of data, which indicated a greater abundance of latesuccession conifers and thus a greater seed source in Miller, more late-succession trees, especially smaller saplings, were expected in Miller.

2. Observations during data collection also indicated reduced tree density in Balch and thus a predicted decreased level of competition, so growth rates were expected to be higher in Balch than in Miller.

3. Based on the distance of Miller from increased urban influences, such as human traffic, and based on in-field observations, the plot was expected to have less invasive species.

4. Finally, due to species composition and distance from urban disturbances, such as soil compaction, spatial complexity was expected to be greater in Miller than in Balch. 


\section{CHAPTER 4: RESULTS}

By exploring stand composition and condition in several different manners, size distribution and compositional differences emerge between the Miller and Balch sites. In Figures 4.1 and 4.2, the dbh of every tree was plotted against its respective height. The scatter plot matrices for tree height and width immediately illustrate the differing number of trees in the Miller and Balch sites, and their differing size distributions.

Figure 4.1. Scatter plot matrix of tree height $(\mathrm{cm})$ over tree $\mathrm{dbh}(\mathrm{cm})$ for predominate tree species in the Balch permanent plot $(\mathrm{ABGR}=$ Abies grandis, $\mathrm{ACMA}=$ Acer macrophyllum, ALRU = Alnus rubra, PSME $=$ Pseudotsuga menziesii, THPL $=$ Thuja plicata, \& TSHE $=$ Tsuga heterophylla $)$.

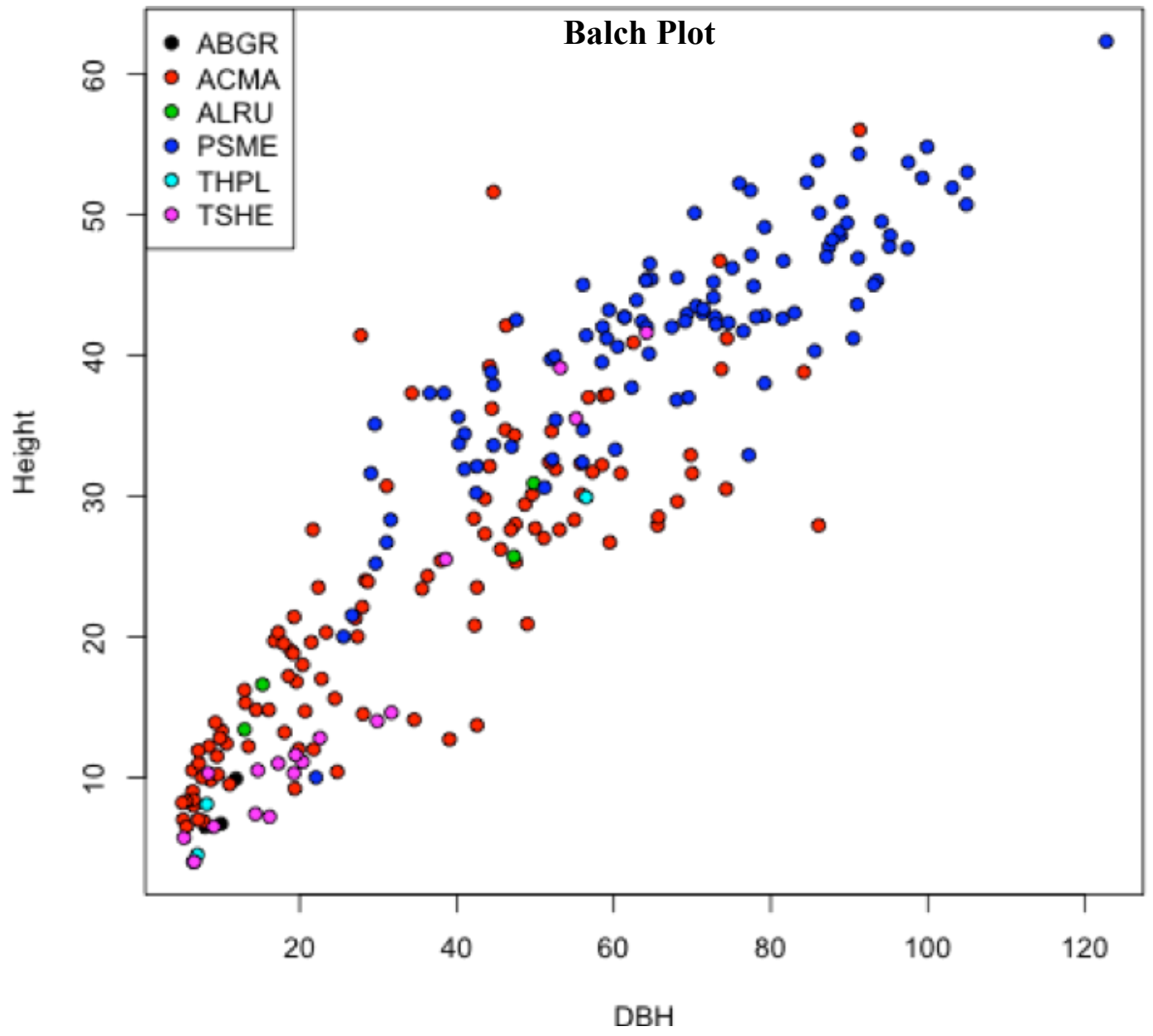


Figure 4.2. Scatter plot matrix of tree height $(\mathrm{cm})$ over tree $\mathrm{dbh}(\mathrm{cm})$ for predominate tree species in the Miller permanent plot $(\mathrm{ABGR}=$ Abies grandis, $\mathrm{ACMA}=$ Acer macrophyllum, ALRU = Alnus rubra, PSME $=$ Pseudotsuga menziesii, THPL $=$ Thuja plicata, \& TSHE = Tsuga heterophylla).

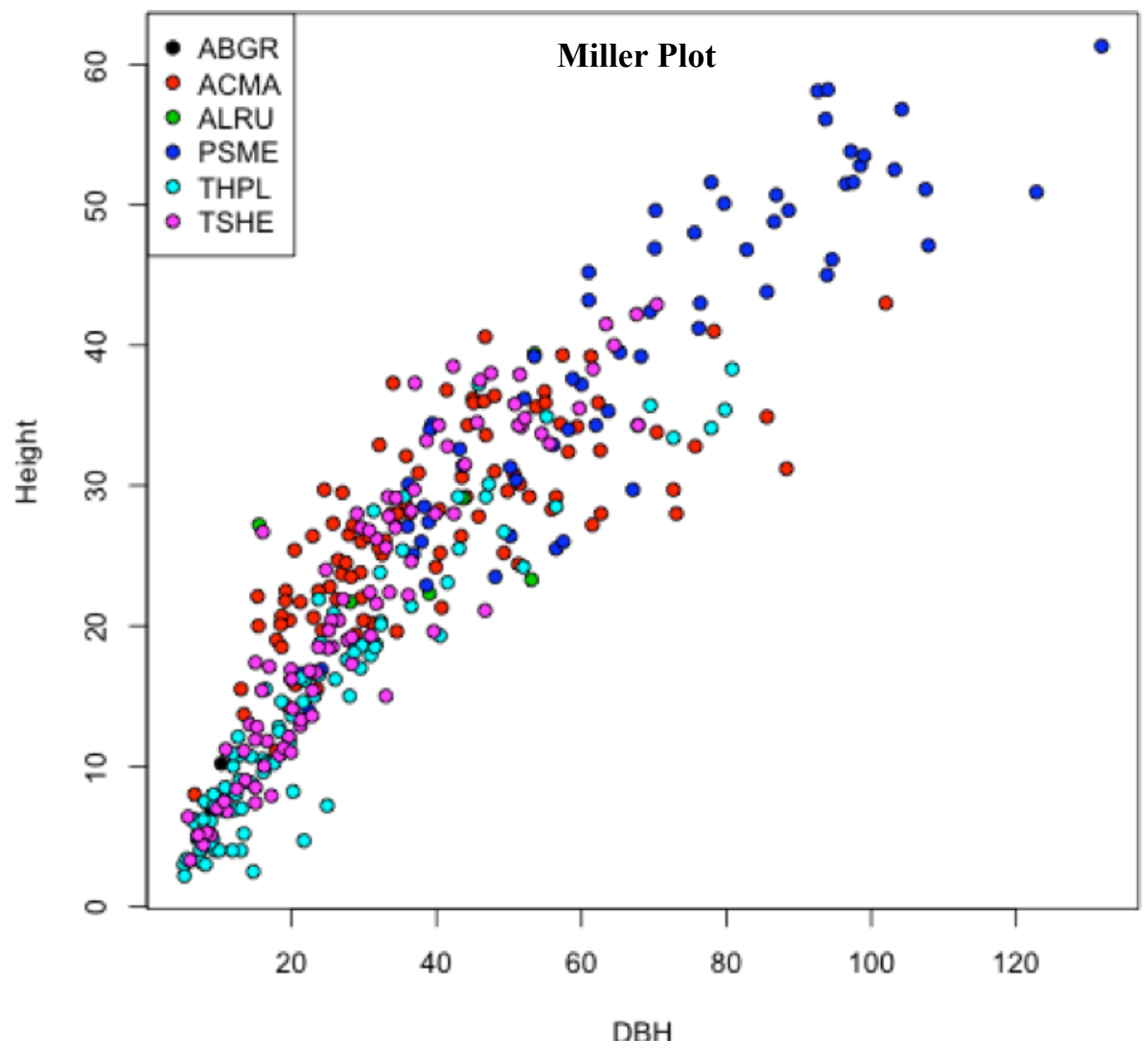

In both the Miller and Balch sites, the largest trees tend to be P. menziesii (PSME). In the Balch plot, the next largest group of trees is A. macrophyllum (ACMA), which cluster near the lowest height and width values, and then spread to illustrate several medium and large trees throughout the plot. In the Miller site, several medium and large A. macrophyllum are also represented, but the species does not cluster as much in the lower size categories. Instead, the Miller site shows a greater abundance of T. plicata (THPL) and T. heterophylla (TSHE), which are documented 
late successional species. Figure 4.3 and 4.4 illustrate the size distribution of the dominant conifer species in both sites, more clearly elucidating a major compositional difference.

Figure 4.3. Scatter plot matrix of tree height $(\mathrm{cm})$ over tree dbh $(\mathrm{cm})$ for dominant conifer species in the Balch permanent plot.

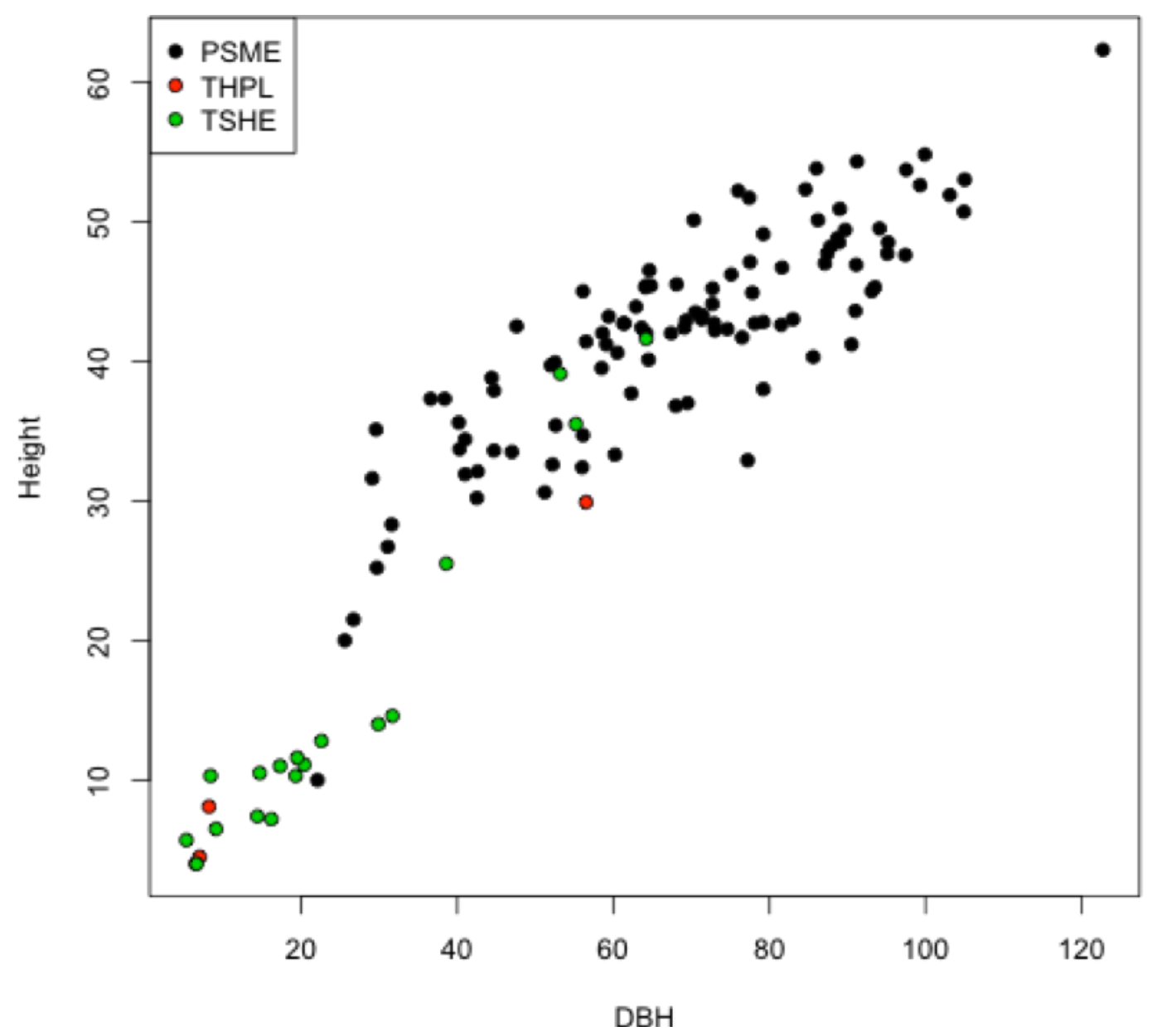

Figure 4.3 and 4.4 illustrate a preeminent structural difference among the conifer species in the Miller and Balch plots. Although more P. menziesii (PSME) currently grow in the Balch site, there is a drastically greater abundance of smaller $T$. plicata (THPL) and T. heterophylla (TSHE) in the Miller site. Specifically, Miller has 92 more T. plicata and 77 more T. heterophylla than Balch, while Balch has 42 more 
P. menziesii than Miller. Overall, there are 110 more trees in the Miller site than in Balch and the shade-tolerant conifer species comprise most of that difference.

Figure 4.4. Scatter plot matrix of tree height $(\mathrm{cm})$ over tree dbh $(\mathrm{cm})$ for dominant conifer species in the Miller permanent plot.

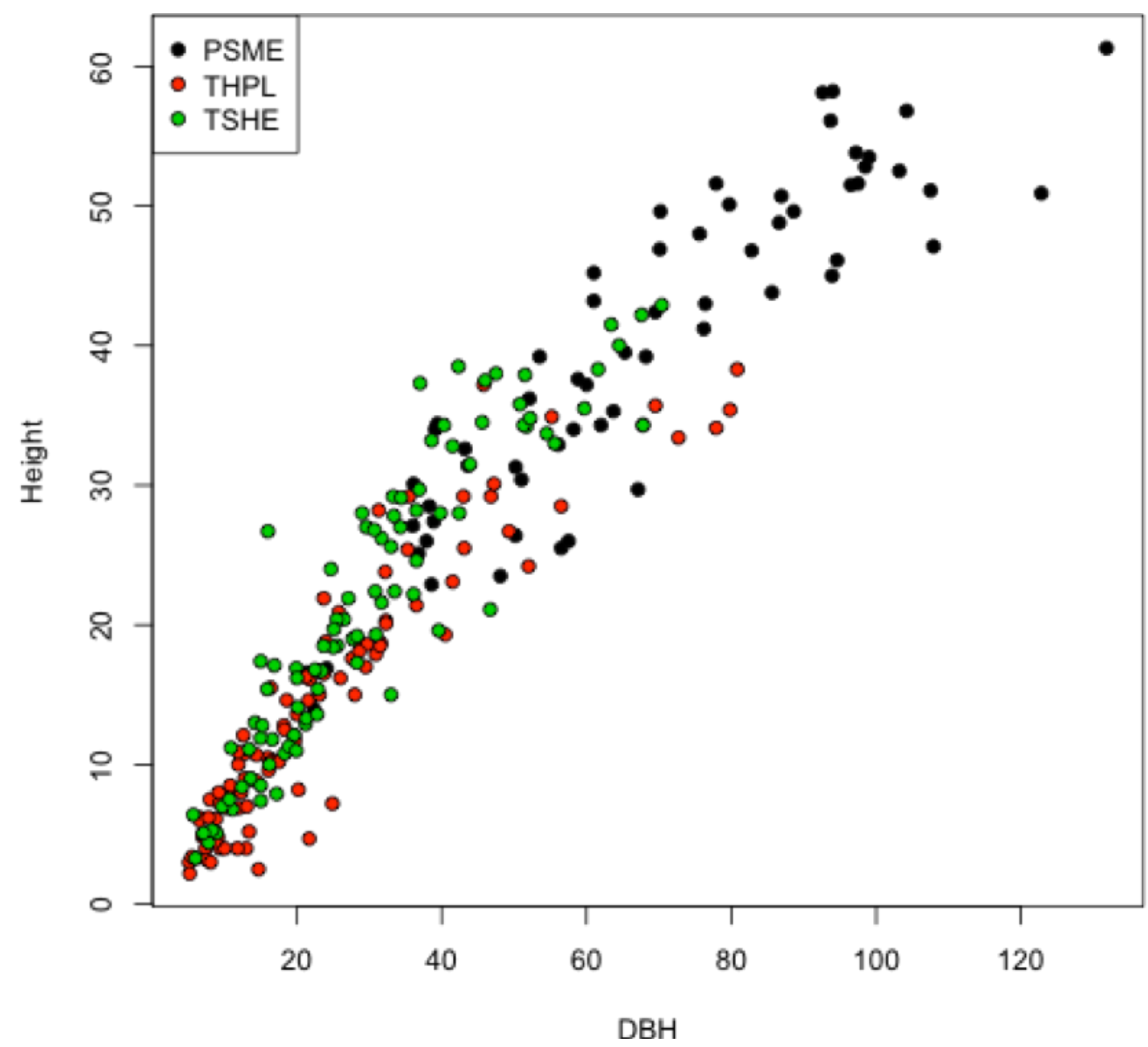

When the age variable from the dated cores is compared between plots, another layer of compositional difference begins to emerge. Some interesting results manifest when the collected tree ages are compared side by side. The $P$. menziesii trees that were cored and dated in both the Balch and Miller plots show a similar range of ages (Figure 4.5), which complements the comparable size distribution of the species in 
Figure 4.5

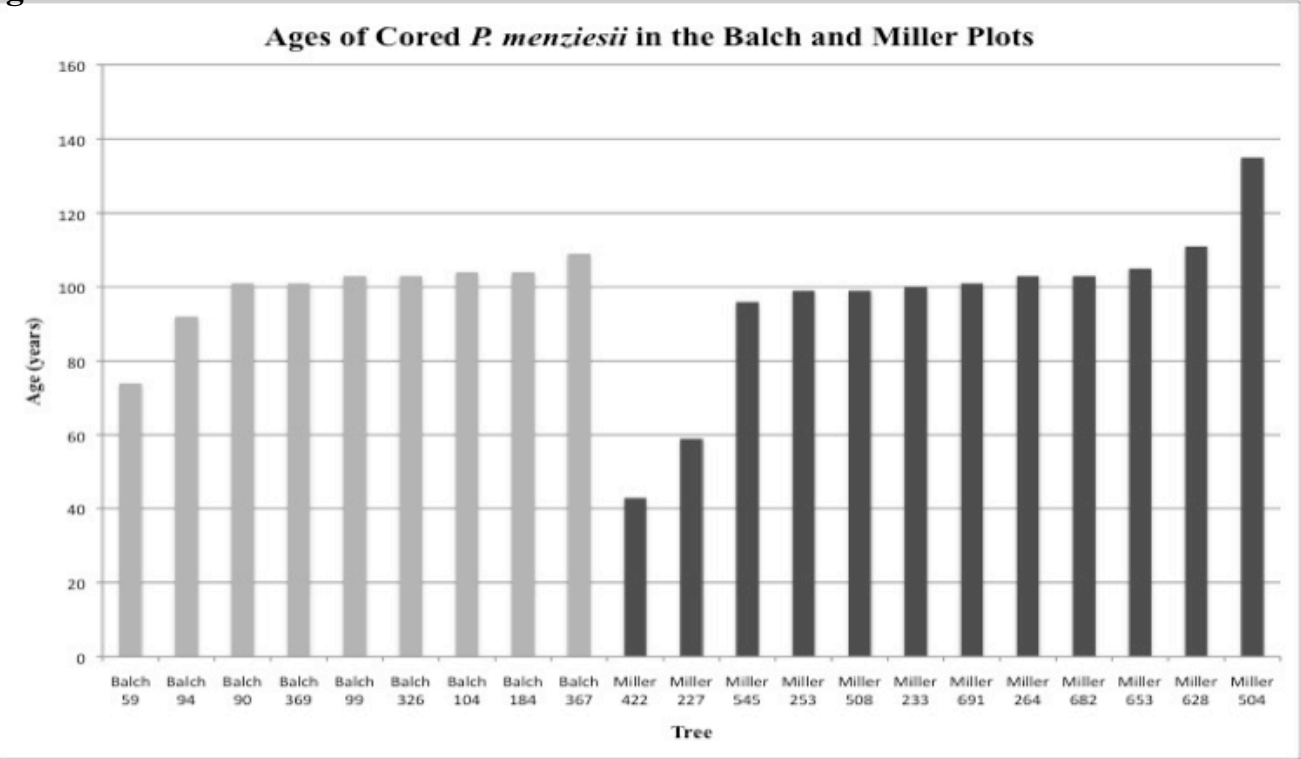

Figure 4.6

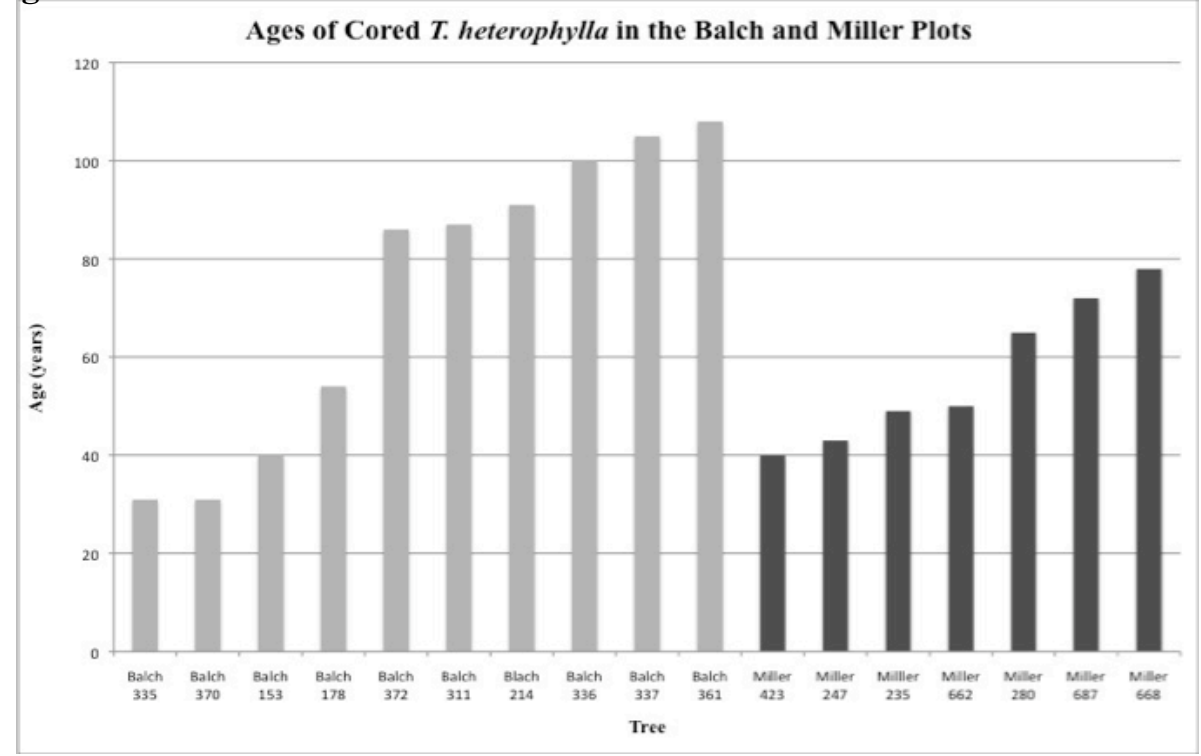

Figures 4.5 and 4.6. Bar graphs of the ages determined from tree rings in P. menziesii and T. heterophylla species in the Balch and Miller plots.

Figures 4.3 and 4.4. Most sampled P. menziesii in Balch and Miller are somewhere around 100 years old at breast height. On the other hand, the age range of $T$. heterophylla in the Balch site is much broader than that in Miller (Figure 4.6). T. 
heterophylla in Balch ranged from 31 years old to 105 years old at breast height, while those sampled in Miller ranged only form 40 to 78 .

When the ages of the cored trees were plotted against their respective height and dbh measurements, Miller again illustrates its greater abundance of younger, smaller T. heterophylla, while Balch evidences more mature trees (Figure 4.7).
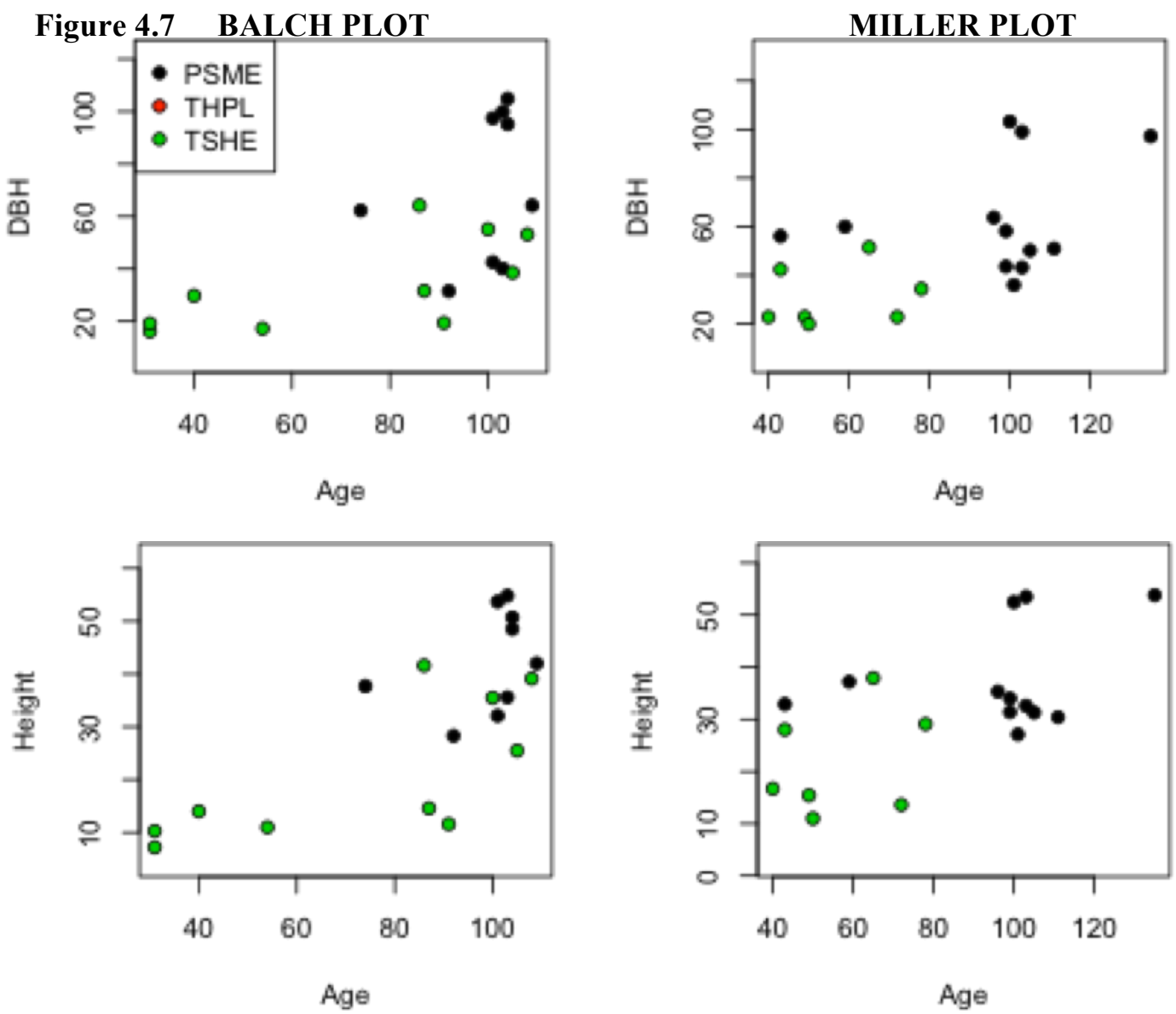

Figure 4.7. Scatter plots of tree height and tree dbh as a function of age, in the Balch and Miller plots.

Interestingly, while most of the T. heterophylla in Balch are older, the sizes of the younger T. heterophylla in Miller are comparable. The results presented in Figure 4.7 for P. menziesii illustrate a pattern similar to the conifer scatter plot matrices (Figures 4.3 and 4.4) and to the tree age bar graphs (Figure 4.5), in that Balch and Miller share 
similar height, width, and age ranges for the species. Although, Figure 4.7 does better illustrate a clustering of $P$. menziesii in Miller around the 100 year old mark, while the majority of the sampled trees in Balch are slightly older than 100 .

The distribution of the cored trees into age classes is illustrated in Figure 4.8.

Figure 4.8. Bar graph of age class distribution for all dated trees in the Balch and Miller plots.

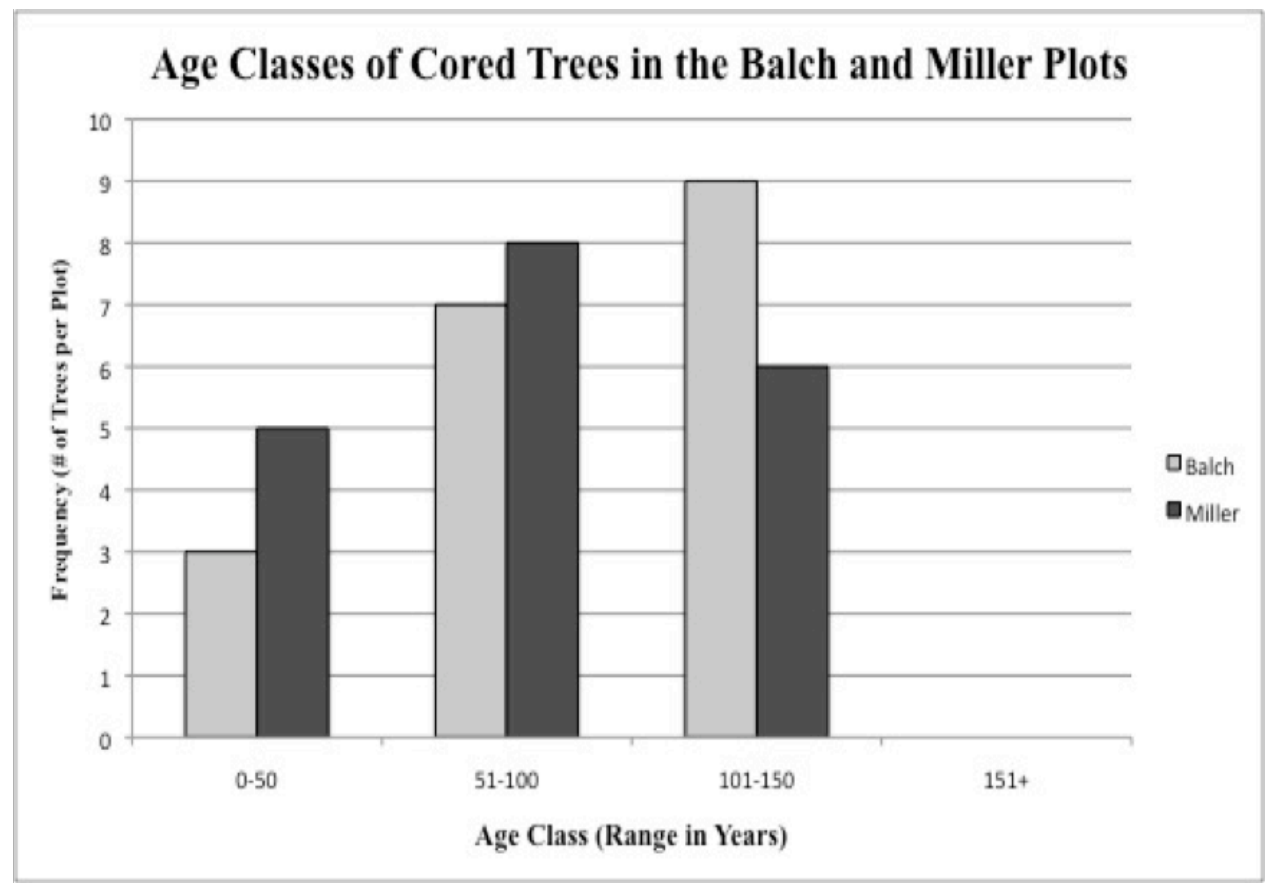

Akin to Figure 4.7, Figure 4.8 shows a greater abundance of young trees in the Miller plot. Miller has more trees aged 0-50 years old, and more trees aged 51-100, than Balch, which has a third more trees aged 101-150 than Miller. The mean and median ages of the two species cored, and the mean and median ages of the total dated trees in the plots, are all higher in Balch than they are in Miller (Table 4.9). Consequently, from the data gathered during the summer of 2010, it appears that the Balch plot is older than the Miller plot. There were no trees over 150 years old in either site. 
Table 4.9 Includes the mean and median ages for P. menziesii and T. heterophylla in the Balch and Miller plots, and the mean and median ages of all dated cores in the plots.

\begin{tabular}{|c|c|c|c|c|c|c|}
\hline PLOT & $\begin{array}{c}\text { Mean } \\
\text { Age } P . \\
\text { menziesii }\end{array}$ & $\begin{array}{c}\text { Mean Age } \\
T . \\
\text { heterophylla } \\
\end{array}$ & $\begin{array}{c}\text { Median } \\
\text { Age } P . \\
\text { menziesii }\end{array}$ & $\begin{array}{c}\text { Median } \\
\text { Age } T . \\
\text { heterophylla } \\
\end{array}$ & $\begin{array}{l}\text { Mean } \\
\text { Age } \\
\text { Plot } \\
\end{array}$ & $\begin{array}{c}\text { Median } \\
\text { Age } \\
\text { Plot } \\
\end{array}$ \\
\hline Balch & 99 & 73.3 & 103 & 86.5 & 85.5 & 100 \\
\hline Miller & 96.2 & 56.7 & 100.5 & 50 & 81.6 & 96 \\
\hline
\end{tabular}

Average growth rates were determined by taking the width of each tree over its age in years. Mean growth rates are presented in Figure 4.10 and Figure 4.11 and illustrate that the average growth rates for P. menziesii in the Balch and Miller plots are fairly similar (Figure 4.10), while the growth rates for T. heterophylla differ more (Figure 4.11). The variable growth rates indicate that although Balch exhibits a greater range in tree ages (Figure 4.6), the T. heterophylla in Miller are growing at a faster pace. 


\section{Figure 4.10}

Mean Growth Rates (cm/year) of T. heterophylla in Balch and Miller Plots

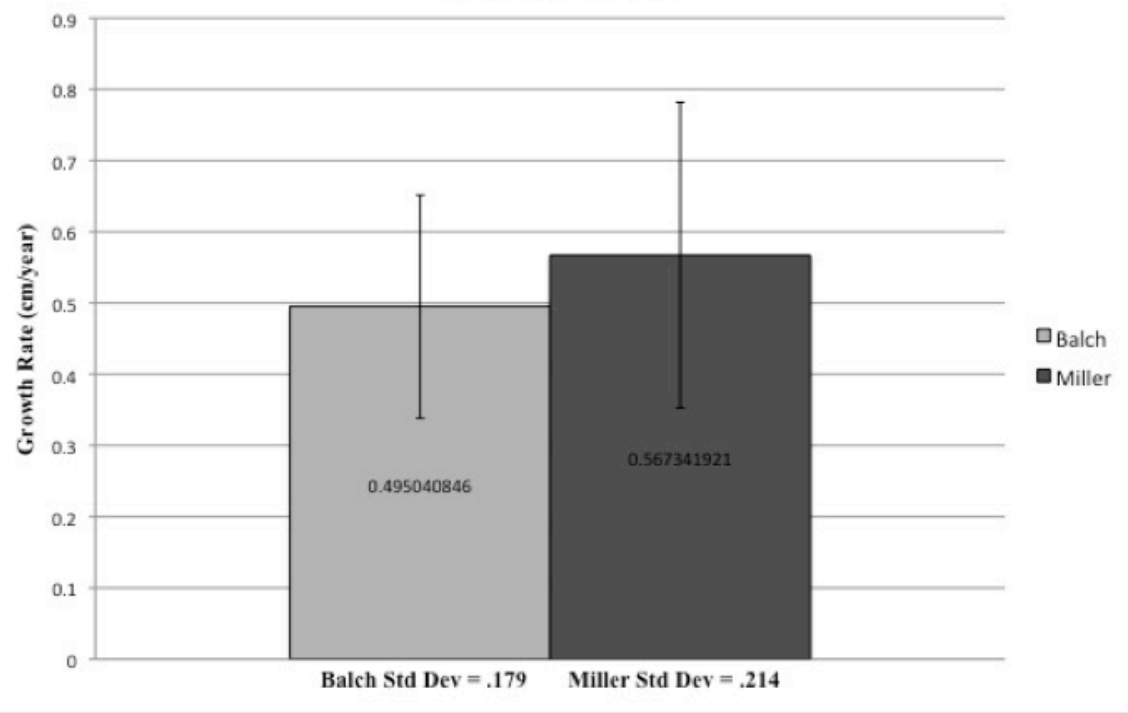

Figure 4.10. Average mean growth rates of T. heterophylla in the Balch and Miller plots.

Figure 4.11.

Mean Growth Rates (cm/year) of P. menziesii in Balch and Miller Plots

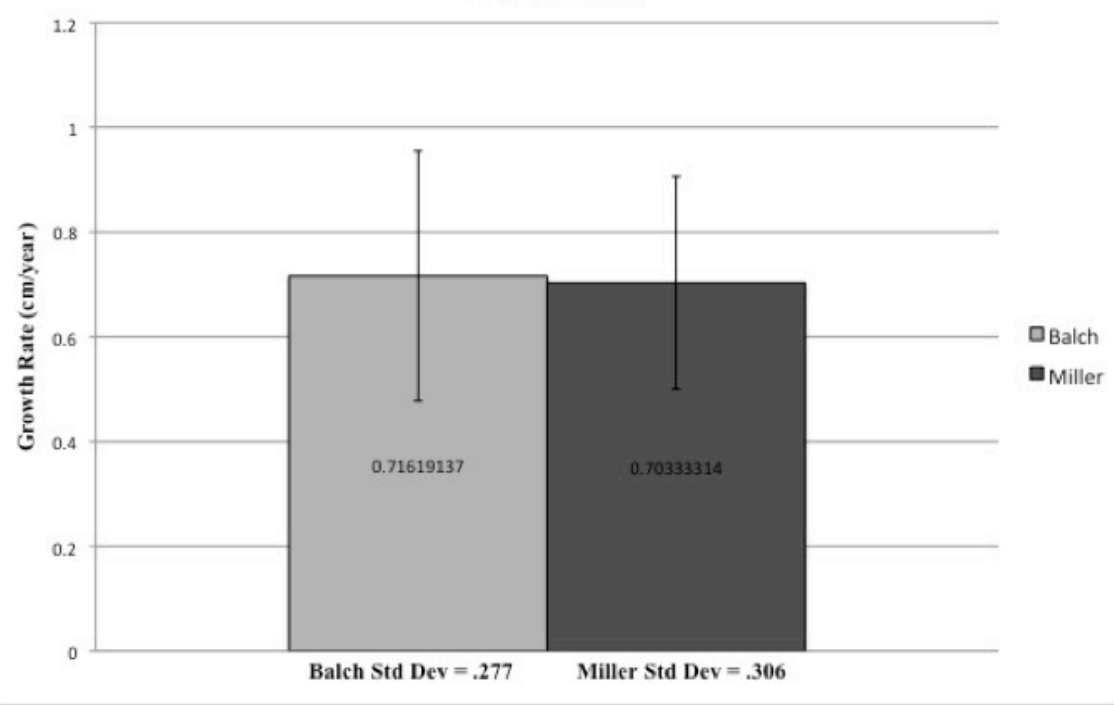

Figure 4.11. Average mean growth rates of $P$. menziesii in the Balch and Miller plots. 
Histograms including tree dbh were created for the Balch and Miller plots.

Figure 4.12 illustrates the dbhs of all trees in the Balch plot, while Figure 4.13

Figure 4.12 \& 4.13 Histograms of every tree dbh in the Balch \& Miller plots
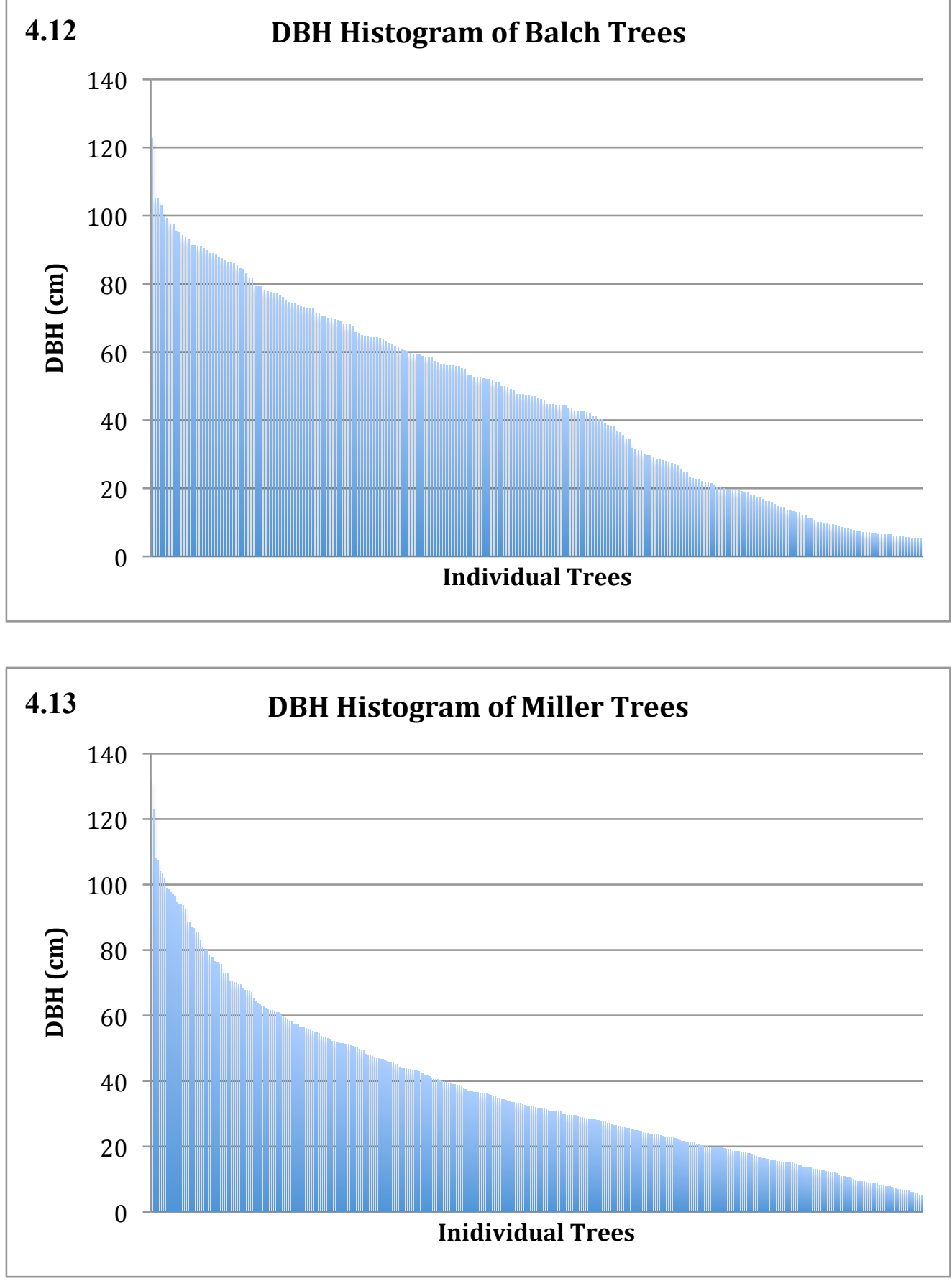
illustrates those of Miller. The trees in the Miller plot more closely follow the reverse J-curve pattern of natural forest stand development than do the trees in the Balch.

Mean tree dbh was compared in order to further explore differences in stand condition between sites. A bar graph of mean tree dbh for each species is portrayed in Figure 4.14. In all species that were present in both sites, besides $A$. grandis, the trees in Miller had a greater mean dbh than those in Balch. However, when the mean dbh of the most prominent species in each plot (A. macrophyllum, P. menziesii, $T$.

heterophylla, and T. plicata) were statistically compared, only A. macrophyllum showed a significant difference. Two-sample t-tests results indicate that the mean dbh of $A$. macrophyllum trees in the Miller plot is significantly greater than that in Balch

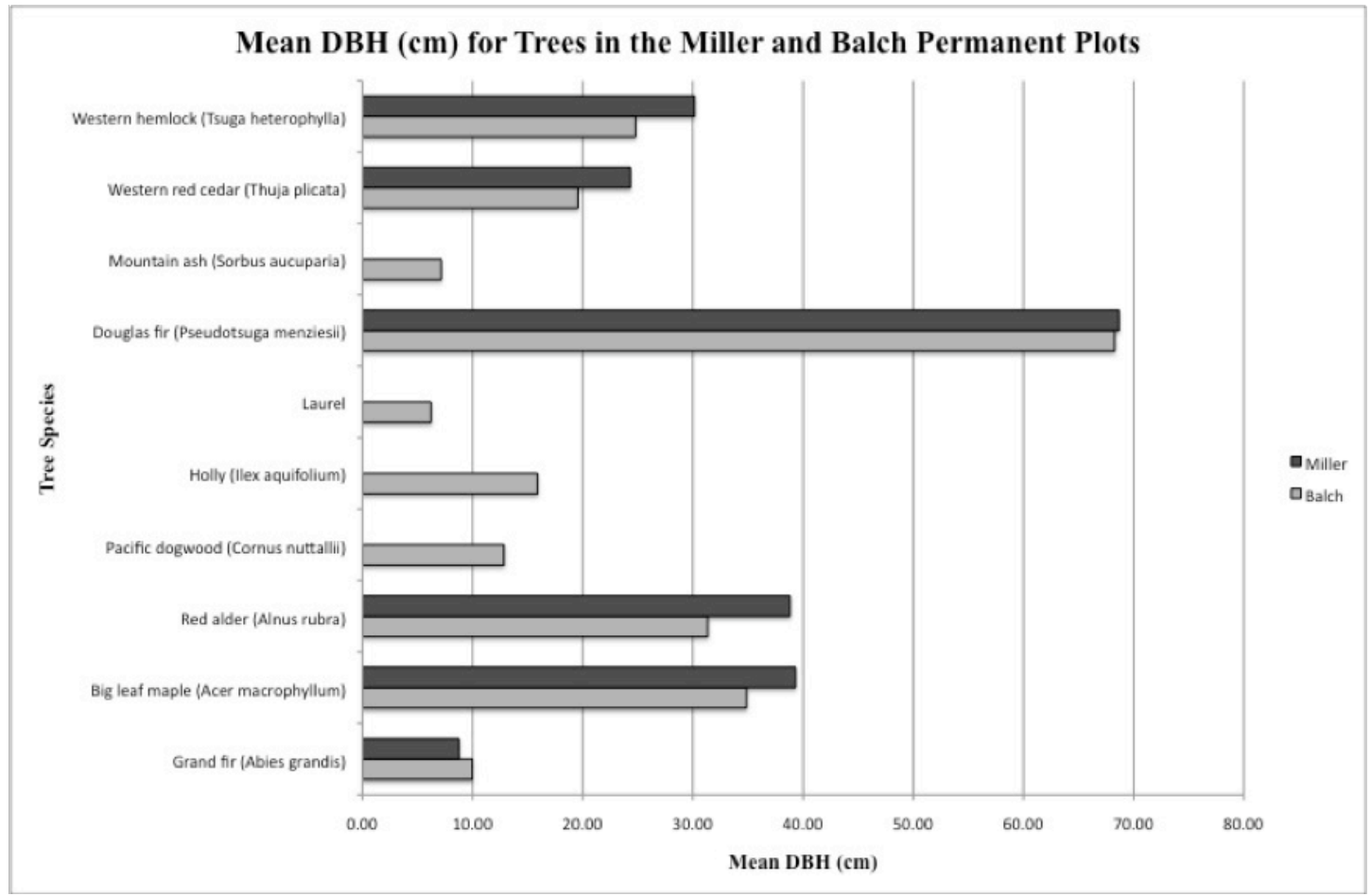

Figure 4.14. Mean dbh by species for trees in the Balch and Miller plots. Balch in light gray, Miller in dark gray. 
(Table 4.15). There were not enough $T$. plicata in both sites to formally compare means.

Table 4.15

\begin{tabular}{|c|c|c|c|c|c|}
\hline $\begin{array}{c}A . \\
\text { Macrophyllum }\end{array}$ & $\begin{array}{c}\text { Mean } \\
\text { DBH }\end{array}$ & $\begin{array}{c}\text { Median } \\
\text { DBH }\end{array}$ & T-Value & df & P-Value \\
\hline Balch & 34.88 & 31.10 & \multirow{2}{*}{-2.89} & \multirow{2}{*}{209} & \multirow{2}{*}{0.0042} \\
\hline Miller & 39.12 & 34.55 & & & \\
\hline P. menziesii & $\begin{array}{c}\text { Mean } \\
\text { DBH }\end{array}$ & $\begin{array}{c}\text { Median } \\
\text { DBH }\end{array}$ & T-Value & df & P-Value \\
\hline Balch & 68.27 & 69.30 & \multirow{2}{*}{0.26} & \multirow{2}{*}{163} & \multirow{2}{*}{0.7941} \\
\hline Miller & 68.66 & 66.20 & & & \\
\hline $\begin{array}{c}T \\
\text { heterophylla }\end{array}$ & $\begin{array}{c}\text { Mean } \\
\text { DBH }\end{array}$ & $\begin{array}{c}\text { Median } \\
\text { DBH }\end{array}$ & T-Value & df & P-Value \\
\hline Balch & 24.81 & 19.40 & \multirow{2}{*}{-1.76} & \multirow{2}{*}{111} & \multirow{2}{*}{0.0810} \\
\hline Miller & 30.14 & 27.70 & & & \\
\hline T. plicata & $\begin{array}{c}\text { Mean } \\
\text { DBH }\end{array}$ & $\begin{array}{c}\text { Median } \\
\text { DBH }\end{array}$ & T-Value & df & P-Value \\
\hline Balch & 19.55 & 7.60 & \multirow{2}{*}{ N/A } & \multirow{2}{*}{ N/A } & \multirow{2}{*}{$\mathbf{N} / \mathbf{A}$} \\
\hline Miller & 24.3 & 18.60 & & & \\
\hline
\end{tabular}

Table 4.15. Includes the mean and median dbh values for the dominant tree species in the Balch and Miller plots and two-sample t-test results from a statistical comparison of mean dbh values. "df" = degrees of freedom. The significantly different means are highlighted in gray.

Mean heights of all species in both plots were also graphically and statistically compared. A bar graph of mean tree heights for each species is portrayed in Figure 4.16. In most species that were present in both sites, the trees in Miller had greater mean heights than in Balch. Yet, mean heights of $P$. menziesii and A. grandis in Balch appear greater than in Miller (Figure 4.16). When statistically compared, though, $P$. menziesii was not significantly different between the sites, although A.macrophyllum and T.heterophylla were. Both A. macrophyllum and T. heterophylla were significantly taller in Miller than in Balch (Table 4.17). 
Figure 4.16 Mean height by species for trees in the Balch and Miller plots

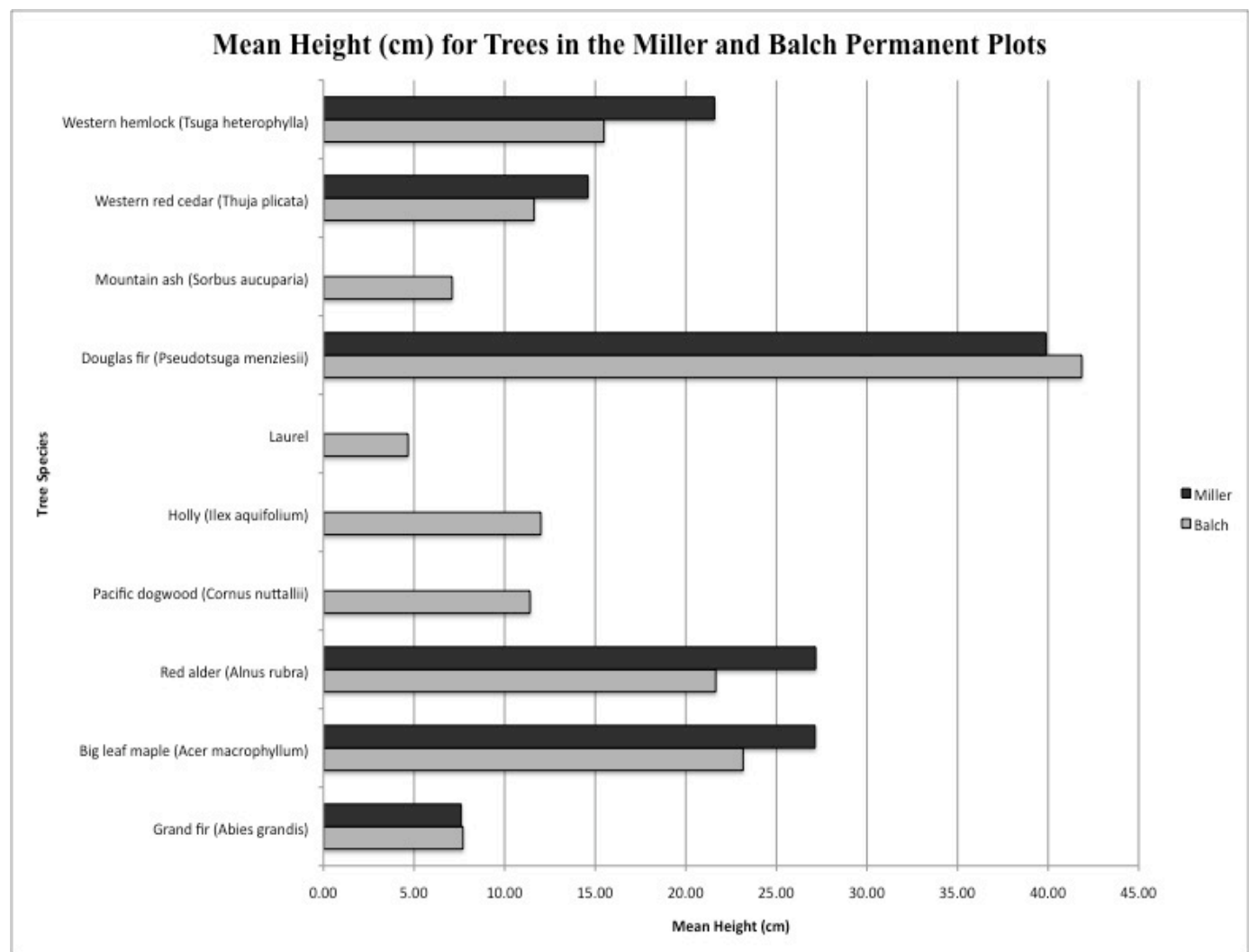

\begin{tabular}{|c|c|c|c|c|c|c|}
\hline $\begin{array}{c}A . \\
\text { Macrophyllum }\end{array}$ & $\begin{array}{c}\text { Mean } \\
\text { Height }\end{array}$ & $\begin{array}{c}\text { Median } \\
\text { Height }\end{array}$ & $\begin{array}{c}\text { T- } \\
\text { Value }\end{array}$ & df & P-Value & $\begin{array}{c}\text { Confidence } \\
\text { Interval }\end{array}$ \\
\hline Balch & 23.15 & 23.40 & \multirow{2}{*}{-3.13} & \multirow{2}{*}{209} & \multirow{2}{*}{0.0020} & \multirow{2}{*}{$\begin{array}{c}-6.49 \text { to }- \\
1.47\end{array}$} \\
\hline Miller & 27.14 & 27.25 & & & & \\
\hline P. menziesii & $\begin{array}{l}\text { Mean } \\
\text { Height }\end{array}$ & $\begin{array}{c}\text { Median } \\
\text { Height }\end{array}$ & $\begin{array}{c}\text { T- } \\
\text { Value }\end{array}$ & df & P-Value & $\begin{array}{r}\text { Con } \\
\text { In }\end{array}$ \\
\hline Balch & 41.90 & 42.70 & \multirow{2}{*}{1.30} & \multirow{2}{*}{163} & \multirow{2}{*}{0.1926} & \multirow{2}{*}{-1.03 to 5.08} \\
\hline Miller & 39.87 & 40.35 & & & & \\
\hline $\begin{array}{c}T . \\
\text { heterophylla }\end{array}$ & $\begin{array}{c}\text { Mean } \\
\text { Height }\end{array}$ & $\begin{array}{c}\text { Median } \\
\text { Height }\end{array}$ & $\begin{array}{c}\text { T- } \\
\text { Value }\end{array}$ & df & lue & $\begin{array}{c}\text { Confidence } \\
\text { Interval }\end{array}$ \\
\hline Balch & 15.48 & 11.05 & \multirow{2}{*}{-2.19} & \multirow{2}{*}{111} & \multirow{2}{*}{0.0307} & \multirow{2}{*}{$\begin{array}{c}-11.62 \text { to }- \\
0.58\end{array}$} \\
\hline Miller & 21.58 & 19.70 & & & & \\
\hline
\end{tabular}

Table 4.17. Includes the mean and median height values for the dominant tree species in the Balch and Miller plots and two-sample t-test results from a statistical comparison of mean dbh values. "df" = degrees of freedom. The significantly different means are highlighted in gray. 
One of the most beneficial results from this study on tree growth and spatial analysis in Forest Park is the mapped location of each individual tree in the Balch and Miller plots. Figure 4.18 includes the trees in Balch, while Figure 4.19 displays trees in Miller. Figures 4.20 and 4.21 include a dbh class layer as well. All trees are represented by circular points, while the square points are the locations of posts in the permanent plots. 
Figure 4.18

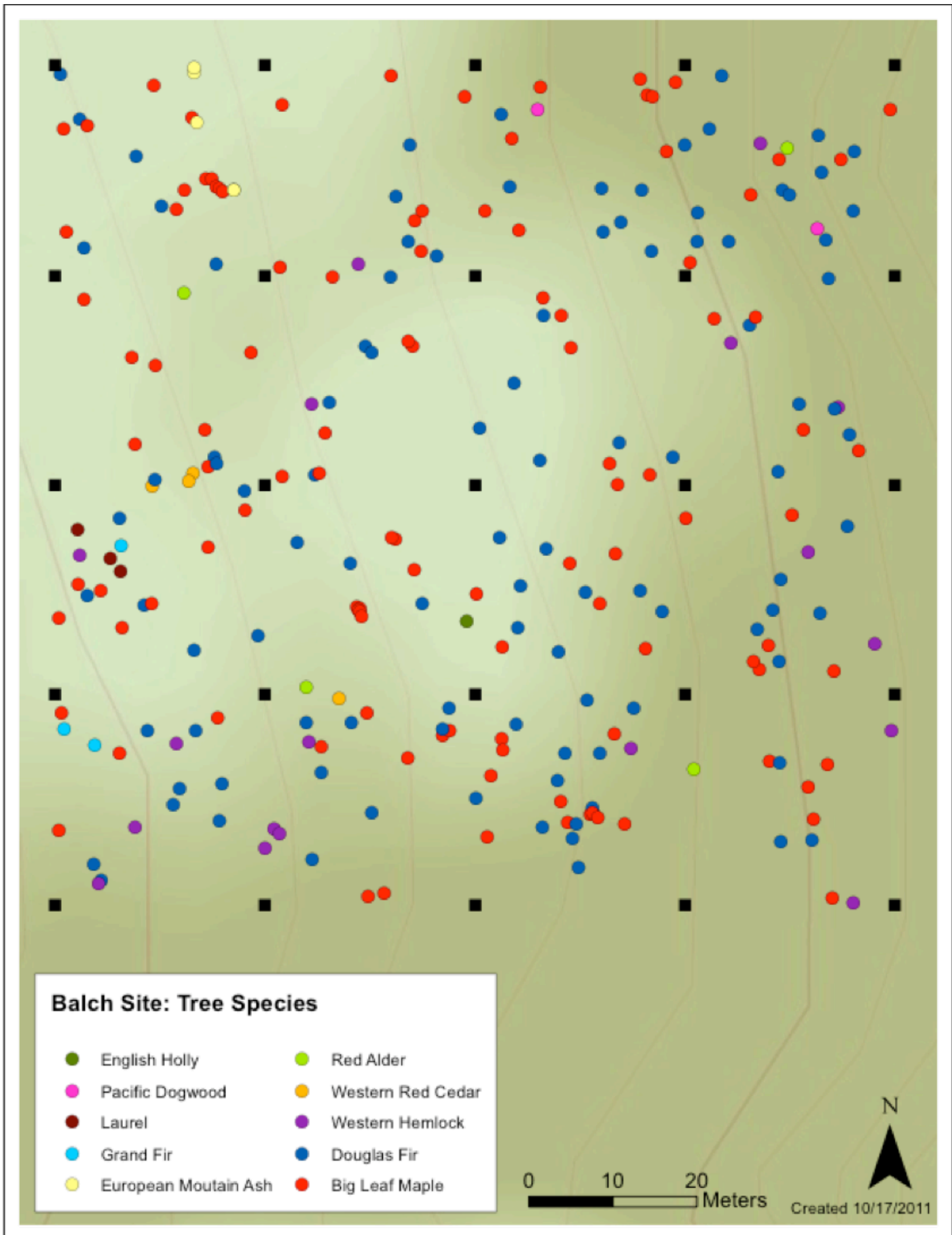

Figure 4.18. A spatially accurate map of every tree in the Balch plot, color-coded by species. English holly = Ilex aquifolium, Pacific Dogwood = Cornus nuttallii, Laurel $=$ Laurus sp., Grand Fir $=$ Abies grandis, E. Mountain Ash $=$ Sorbus sp., Red Alder $=$ Alnus rubra, Western Red Cedar $=$ Thuja plicata, Western Hemlock $=$ Tsuga heterophylla, Douglas Fir = Pseudotsuga menziesii, \& Big Leaf Maple = Acer macrophyllum. 
Figure 4.19

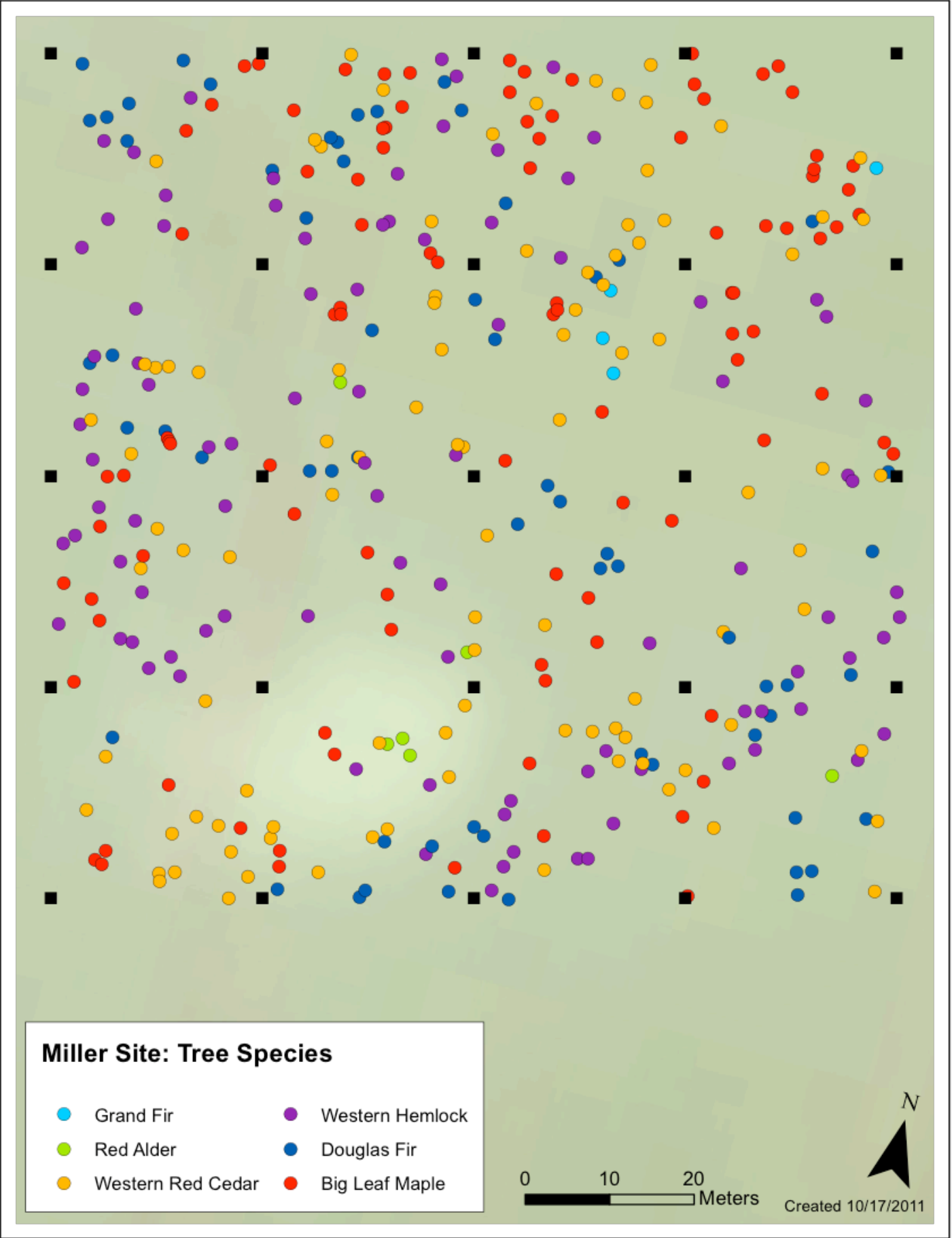

Figure 4.19. A spatially accurate map of every tree in the Miller plot, color-coded by species. Grand Fir $=$ Abies grandis, Red Alder $=$ Alnus rubra, Western Red Cedar $=$ Thuja plicata, Western Hemlock = Tsuga heterophylla, Douglas Fir $=$ Pseudotsuga menziesii, \& Big Leaf Maple = Acer macrophyllum. 
Figure 4.20

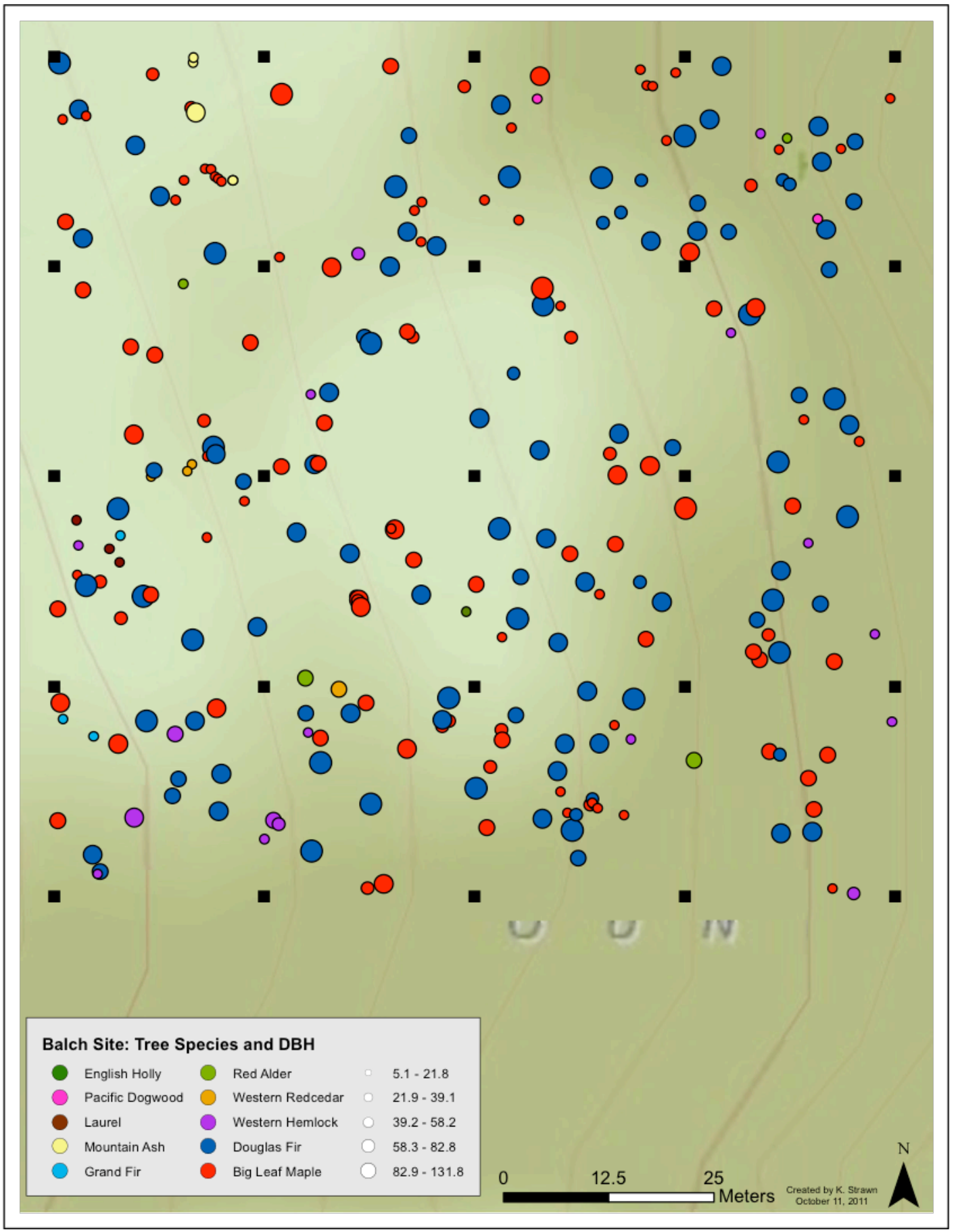

Figure 4.20. A spatially accurate map of every tree in the Balch plot, color-coded by species and represented with variable sized points corresponding to dbh class.

English holly $=$ Ilex aquifolium, Pacific Dogwood $=$ Cornus nuttallii, Laurel $=$ Laurus sp., Grand Fir $=$ Abies grandis, E. Mountain Ash $=$ Sorbus sp., Red Alder $=$ Alnus rubra, Western Red Cedar $=$ Thuja plicata, Western Hemlock $=$ Tsuga heterophylla, Douglas Fir = Pseudotsuga menziesii, \& Big Leaf Maple = Acer macrophyllum. 


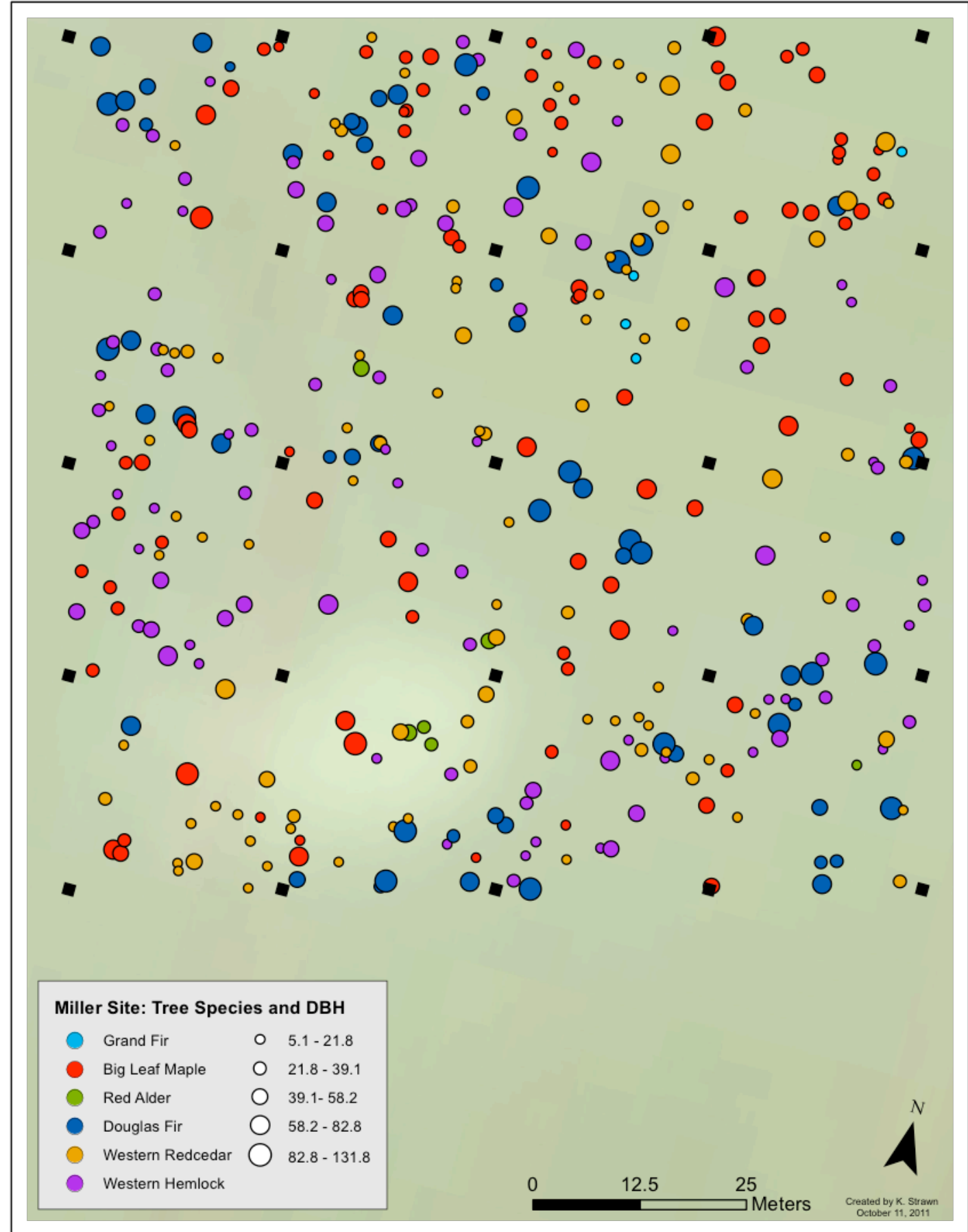

Figure 4.21. A spatially accurate map of every tree in the Miller plot, color-coded by species and represented with variable sized points corresponding to dbh class. Grand Fir $=$ Abies grandis, Red Alder $=$ Alnus rubra, Western Red Cedar $=$ Thuja plicata, Western Hemlock = Tsuga heterophylla, Douglas Fir = Pseudotsuga menziesii, \& Big Leaf Maple $=$ Acer macrophyllum. 
The mapped locations of the trees provide a reference for spatial patterns and species growth occurring in the plots. In Balch, A. grandis occurs sporadically throughout the plot, but the largest individuals are concentrated in the southwestern corner (Figure 4.18). The few T. heterophylla growing in Balch also seem to cluster on the west side of the plot (Figure 4.18). P. menziesii and A. macrophyllum are more or less uniformly dispersed throughout the site. They are the most abundant species, present in every subplot, although $P$. menziesii less so in the northwestern corner (Figure 4.18). In accordance with the other graphical results, P. menziesii represent the largest organisms throughout the site (Figure 4.20). Interestingly, the four A. rubra growing in Balch appear almost equidistant from one another, with one organism in each corner of the plot (Figure 4.18).

Invasive species are also represented in Balch, with a cluster of Laurel growing on the west side (Figure $4.18 \& 4.20$ ). Despite observed efforts to eradicate $I$. aquifolium in the Balch site, one individual still grows just south of the center point of the plot (Figure 4.18). The maps also show the locations of two other species that are present in Balch, but not in Miller. Two C. nuttallii grow in the northeastern corner of the Balch site, while a cluster of Sorbus $s p$. grow in the most northwestern subplot. The difference in sheer abundance of trees and the diversity of species growing between the two sites are most notable in these maps.

The spatial maps of the trees in Balch also evidence an unmanaged trail, or a "bulldozer trail." There is an absence of trees in the western subplots, beginning in the most southwesterly plot and continuing through the plots north of it. Figure 4.22 highlights the track of the unmanaged trail. 


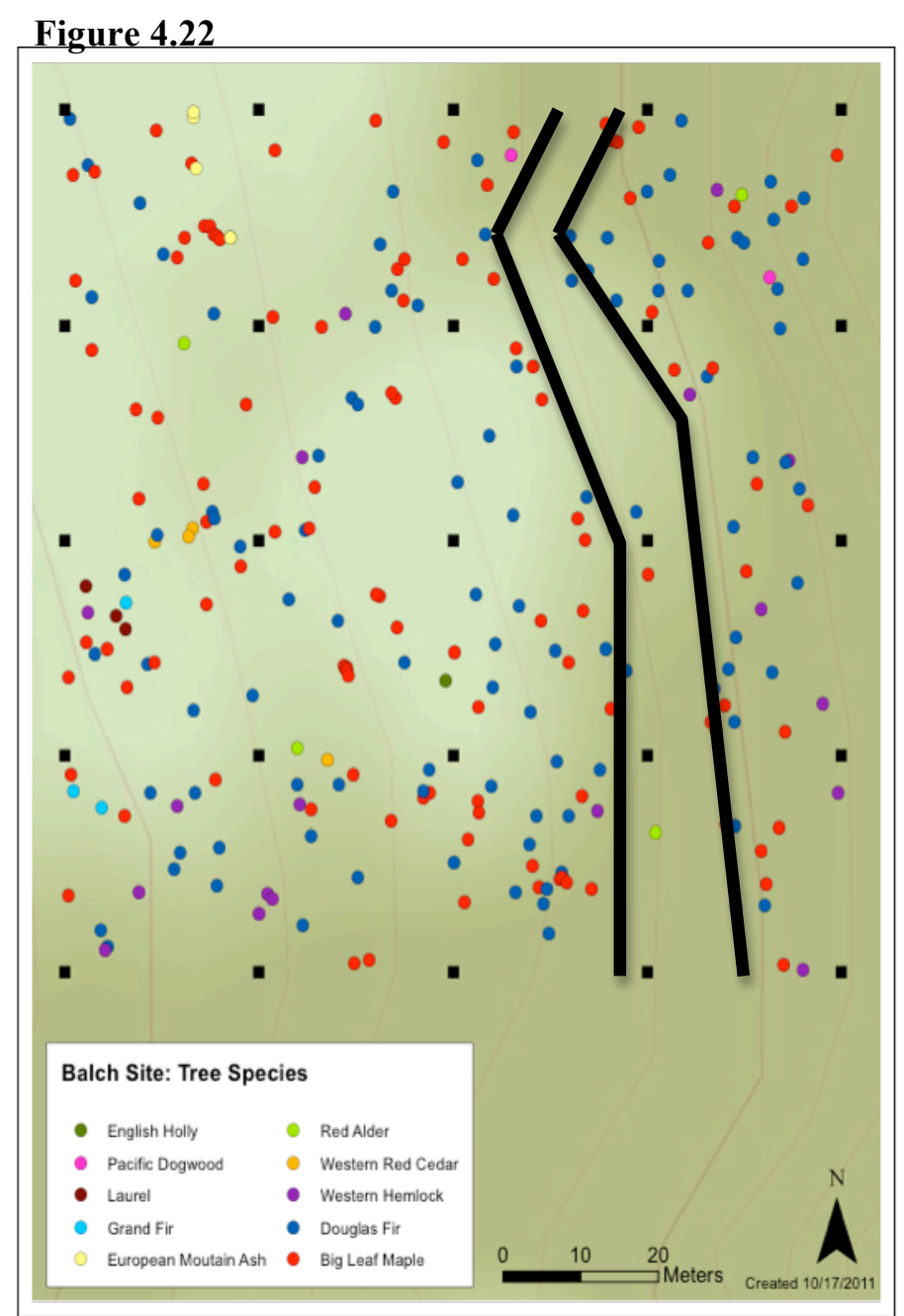

Figure 4.22. A spatially accurate map of every tree in the Balch plot with an unmanaged trail outlined in black.

In the Miller plot, Figure 4.19 and 4.21 illustrate a remarkably greater abundance of $T$. heterophylla and T. plicata. While both species grow profusely throughout the site, Figure 4.21 does elucidate some clustering of $T$. heterophylla in the bottom southeastern corner and in the upper northwestern section. A concentration of large T. plicata grows in the northeastern section of the site (Figure 4.21). Similar to the T. heterophylla, P. menziesii also seems to cluster in the northwestern corner 
and follow a transect diagonal down to the southeastern section of the plot (Figure 4.21). A dominance of A. macrophyllum and T. plicata comprise the opposite northeastern and southwestern sections (Figure $4.19 \& 4.21$ ).

Unlike Balch, no I. aquifolium, C. nuttallii, Sorbus sp., nor Laurus sp. grow in the Miller site (Figure $4.18 \& 4.19$ ). No invasive woody species were found in Miller at all, aside from stumps that evidenced eradicated I. aquifolium. Besides the four dominant species, there is one patch of $A$. grandis in the northeastern corner of Miller (Figure 4.19). A. rubra is present as well, in equally minimal numbers to the Balch site and predominantly in the southern portion of the plot (Figure $4.18 \& 4.19$ ). Since the coordinates of each tree were determined during data collection, the data was also subjected to a semivariogram analysis.

Figure 4.23 illustrates the results of a semivariogram analysis using the Balch tree dbh data. Figure 4.22 illustrates the curve produced from the Miller tree dbh data. The lack of a curve in either plot indicates that if there is any correlation between tree $\mathrm{dbh}$ in the plots, it is highly localized. The Miller plot (Figure 4.24) does not indicate any spatial structuring, represented by the absence of a curve in the semivariogram, and Balch (Figure 4.23) only indicates some spatial structure within a distance of tenmeters. Although this investigation is only able to probe the baseline data collected in the first year of the project, and semivariogram results do not exhibit a spatial correlation for $\mathrm{dbh}$, the potential for these maps and data to be used for future spatial and stand composition analysis is substantial. 
Figure 4.23

Variogram of Balch DBHs

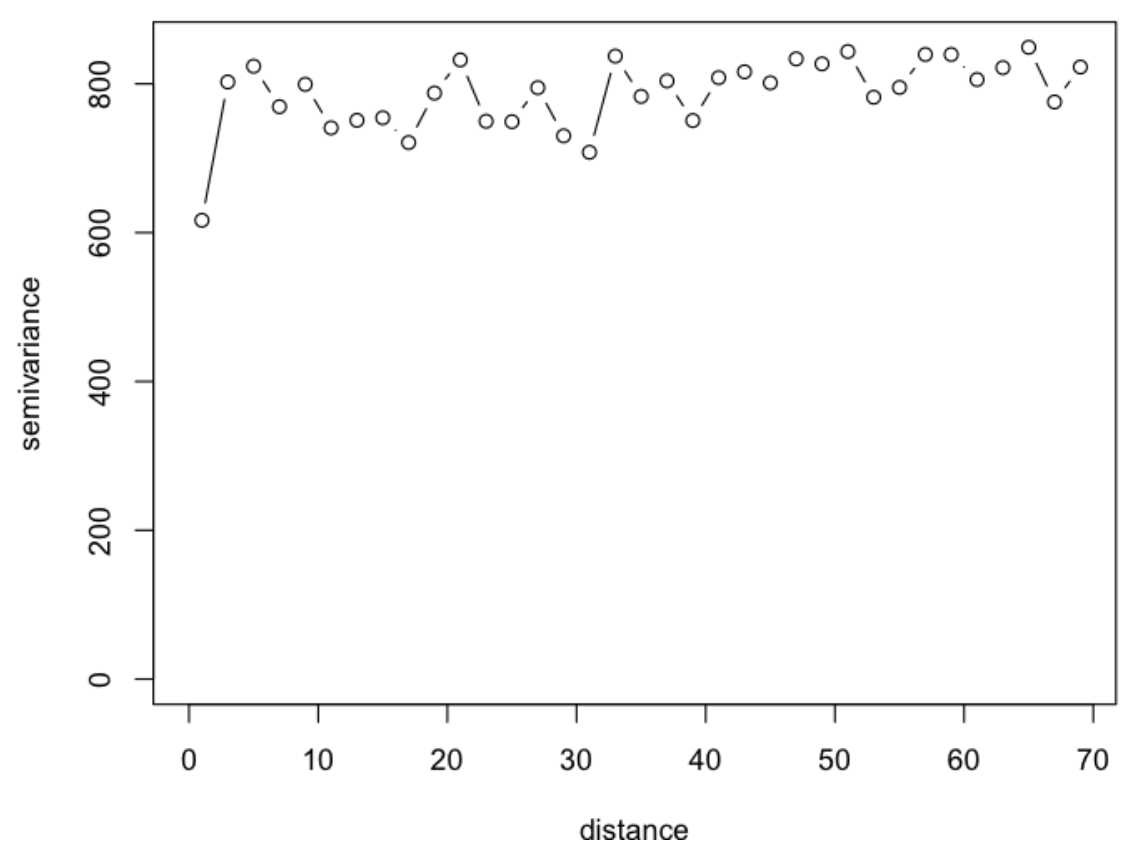

Figure 4.24 Variogram of Miller DBHs

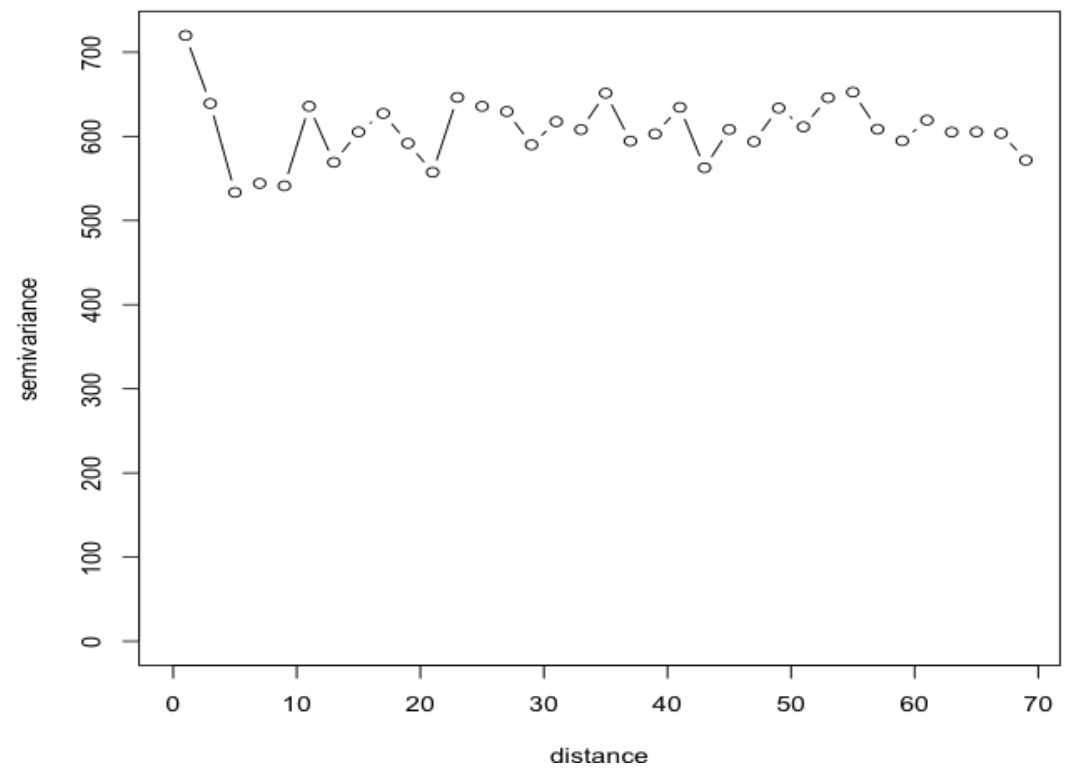

Figure 4.23 and Figure 4.24. Semivariogram results for all dbh data from Balch (4.23) and Miller (4.24) trees. 


\section{CHAPTER 5: DISCUSSION}

\section{Shade-tolerant Recruitment \& Succession in Balch and Miller}

Land use history evidences logging disturbance around the mid-nineteenth and early twentieth centuries in both the Balch and Miller sites. Considering the Franklin et al. (2007) succession theory, and the ages of the $P$. menziesii in the plots, $P$.

menziesii and A. macrophyllum likely established as initial cohorts in both drainages around 100 years ago. However, recruitment of shade-tolerant species in Balch is absent until recently, so species composition and canopy structure between the sites likely diverged around the canopy closure stage. Now, ages of trees indicate that both stands are in the maturation stage of the Franklin et al. (2007) succession theory, but composition among the two is very different.

One of the major compositional and stand condition differences that exist between the Miller and Balch plots concerns the shade-tolerant, and typically late succession species, T. plicata and T. heterophylla. In Miller, the clustering of $T$. plicata and T. heterophylla around the lower height and width values indicates successful recruitment. The reverse J-curve of the Miller plot illustrated in Figure 4.13 also indicates a self-regulating, uneven-aged stand. Consequently, Miller demonstrates a greater potential for following the Franklin et al. (2007) succession model and reaching old growth climax conditions.

While P. menziesii comprise the largest sized trees in both plots at present, the lack of young T. plicata and T. heterophylla in Balch evidence a reduced potential for achieving T. heterophylla zone old growth. Without the recruitment of late succession species, the Balch plot may exhibit a different old growth stand composition, or it may 
take much longer for $T$. plicata and $T$. heterophylla old growth to be reached. The lack of shade-tolerant recruitment may have implications for self-regulation in the stand, especially in light of non-native species invasion. Land use history in Balch, in addition to urban impacts, may also be playing a role in the lack of $T$. plicata and $T$. heterophylla in the stand.

Documented woodcutting camps occurred in Forest Park in the early 1900's and again during the Great Depression. However, the Balch plot is in close proximity to neighborhoods and the urban center, and it is possible that undocumented wood collection occurred in the area for a longer period of time. While most of the large oldgrowth trees in Forest Park were removed by 1860, second growth $T$. plicata and $T$. heterophylla would have been nicely sized for firewood selection by the early and mid 1900's. In addition to undocumented woodcutting, forest fires near the area could have contributed to the lack of shade-tolerant species observed in the plots today.

Two major fires burned near the Balch site, one in 1940 and another in 1951. Although reconstructed maps of the burn areas do not specifically include the location of the Balch plot, it is possible that low intensity fires spread to the location of the site, either as consequence of the major fires, or in other undocumented instances. If fires burned in the Balch area around the mid 1900's, small trees could have been killed off, including second growth $T$. plicata and $T$. heterophylla. Low intensity fires may have also burned off the organic layers of the soil and exposed mineral soil. Although mineral soil is preferential for $P$. menziesii recruitment, it is not favorable to $T$. plicata and T. heterophylla growth. 
Land use history and disturbance surrounding the Balch drainage must also be considered. Although shade-tolerant recruitment is mostly absent in the Balch site, Figure 4.3 does reveal some recent establishment of $T$. heterophylla. It is likely that distance from a seed source is a major factor in shade-tolerant recruitment in the stand. Shade-tolerant seed sources surrounding the Balch plot may have been burned in the 1940 and 1951 fires, or removed for timber. Now, the lack of shade-tolerant species in Balch hinders the seed source for future establishment of $T$. heterophylla and $T$. plicata in the site, but it may just take time for the species to spread. Urban impacts may also be at work, impeding shade-tolerant recruitment and growth.

The Balch creek drainage is more highly trafficked than the Miller drainage, which may contribute to soil compaction and trampling in the stand. Evidence of an undocumented trail, or "bulldozer trail," is present in the Balch plot, and appears on the species map (Figure 4.20). The unmanaged trail may facilitate human traffic into the stand and increase the potential for soil disruption and trampling. Decreased macro-pore space, impeded root penetration, reduced soil oxygen, and increased organic horizon erosion could contribute to a lack of recruitment. Conversely, growth of some non-native invasive species like Ilex aquifolium (English Holly) and Hedera helix (English Ivy) are not as sensitive to compacted soils and may also have a role in the reduced recruitment in Balch.

Non-native invasive species are considerably more prevalent in the Balch plot than they are in Miller. During plot establishment, it was apparent that a massive effort had recently been made to remove I. aquifolium from the Balch site. Several felled trees greater than ten feet in height were present, indicating that until recently $I$. 
aquifolium was competing successfully in the stand. It is unlikely that I. aquifolium were shading out the shade-tolerant $T$. heterophylla and $T$. plicata, but the invasive species could have been competing for soil water and mycorrhizae. In addition, $H$. helix dominates much of the ground cover in Balch. It is possible that allelopathic properties from dense $H$. helix cover may be inhibiting shade-tolerant recruitment and growth. The overtopping of nurse logs by H. helix may also reduce suitable habitat for T. heterophylla. The success of non-native invasive species in Balch is likely a contributing factor to the differences in stand composition and condition in the Miller and Balch plots.

\section{A. macrophyllum and H. Helix in Balch and Miller}

In addition to differences between shade-tolerant species densities, a second major compositional difference between the Balch and Miller plots concerns $A$. macrophyllum and H. helix. Results from this study corroborate results from the Broshot (2009) study where findings indicated that the more urban section of the park was dominated by earlier successional species (A. macrophyllum and P. menziesii). Moreover, the invasion of $H$. helix in Balch is progressed, especially compared to Miller where no $H$. helix was observed. The relationship between A. macrophyllum and H. helix in Balch is important to consider when analyzing the mechanisms that are driving stand composition in the sites.

A. macrophyllum is a dominant species in the Balch stand and comprises much of the canopy. H. helix is a sun-winter annual, that is able to photosynthesize yearround. In Balch, the dominance of deciduous A. macrophyllum in the canopy means that during winter months, the canopy is much more open. Consequently, H. helix is 
able to continually grow throughout the winter and thus, the composition of $A$. macrophyllum in Balch may be facilitating invasion. As a result of the relationship between A. macrophyllum and H. helix, A. macrophyllum could have an indirect role in inhibiting shade-tolerant recruitment via promoting non-native invasion.

\section{Other Invasive Species in the Stands}

Balch also has more non-native invasive woody species than Miller, as supported by the results in Figure 4.18 and 4.20. There are no non-native invasive woody species present in Miller, while I. aquifolium, Laurel and Sorbus sp. still grow in Balch. As previously mentioned, the abundance of H. helix in Balch should also be noted, although it is not captured in the data referenced in this study. The close proximity of Balch to the urban center, and to many residential properties, strongly increases its chance for invasion from horticultural plantings. Additionally, the increased traffic that the stand experiences, increases opportunities for humans to act as vectors and transport non-native invasive species through the Balch drainage. Many removal programs are in place, and I. aquifolium is almost eradicated from the site. But, invasive organisms populate the Miller drainage less, and Parks and Recreation should continue to consider rigorous invasive removal for managing Balch.

\section{Stand Age in Balch and Miller}

The analysis of the tree cores indicates that the Balch stand is overall slightly older than the Miller stand. Mean and median ages for both P. menziesii and T. heterophylla are greater in Balch, as is total plot mean and median age. Balch also has more trees in the 101 to 150 year old age class, which may be due to the proximity of the Balch site to the urban center. Zhou et al. (2011) found that forest cover tended to 
be more stable closer to the urban center because further away, development was still occurring. Broshot (2009) also surmised that Forest Park sites closer to city had been free of major disturbance for longer. Age results from the Balch plot support this hypothesis. The Balch drainage was one of the earliest parts included in the Forest Park perimeter and abuts many high-priced residential properties. The trees may have been allowed to grow longer in the Balch site for aesthetic reasons.

It is important to note that the true ages of trees in the drainage may not be reflected in the data collected. It is possible that the oldest trees in either stand may be species other those use in this analysis, P. menziesii and T. heterophylla. In order to more accurately ascertain the age of the Balch and Miller stands, cores should be taken from sufficient $T$. plicata. In addition, dating the cores that were taken from the $A$. macrophyllum would add a beneficial layer to the analysis. Nonetheless, since the cores were used to determine average growth rates for the sampled species, the data is very helpful for exploring growth rates in the sites.

\section{P. menziesii and T. heterophylla Growth in Balch and Miller}

A comparison of growth rates for P. menziesii in Balch and Miller reveals that the species is growing at a similar pace in both sites, averaging around .70 centimeters per year. However, when tree density and stand composition differences are considered, it is somewhat surprising that the species is growing so similarly in both plots. P. menziesii is a shade-intolerant species and Miller has over 100 more trees than Balch, most of them conifer. Since there are fewer trees in Balch, and by comparison many of them are deciduous, $P$. menziesii would be expected to grow more rapidly than in the densely populated Miller. However, P. menziesii in Miller are 
the tallest trees in the stand and comprise more of the canopy than the understory. The P. menziesii may already be at a height where density does not affect growth. $T$. heterophylla, on the other hand, are growing at a more rapid rate in Miller than in Balch.

As determined by the cored trees, T. heterophylla in Miller are growing .072 centimeters per year more than in Balch. The decreased growth rate of T. heterophylla in Balch could be the result of non-native invasive competition, canopy characteristic differences, or urban influences such as soil compaction. T. heterophylla demands a continuous supply of water and decreased macro-pore space associated with compacted soils may inhibit growth.

In order to more fully explore the influences on tree growth variables in the Balch and Miller drainages, an exploration of the soil profile and light level is essential. A classification of soil type and nutrient level should be garnered in order to better understand what is contributing to growth rates below ground. Since different species require different nutrient loads, soil drainage, and $\mathrm{pH}$ levels, exploring the soil profile is an important next step in the long-term look at these plots. In addition, seasonal light levels within the plots should be explored to more fully survey the affects of canopy closure on species growth in the sites.

\section{Mean tree height and width in Balch and Miller}

The significantly greater mean tree heights and $\mathrm{dbh}$ for $A$. macrophyllum in Miller, and the significantly greater height of T. heterophylla in Miller initially seem contradictory to the age and plot density data. Mean tree dbh and mean tree height might be expected to be greater in Balch, due to a less dense stand and the expectation 
that trees were older. However, A. macrophyllum ages were not included in this study and thus, the species may in fact be older and larger in Miller. Density in the Miller stand is also mostly comprised of smaller, shade-tolerant trees below the canopy. Currently, many A. macrophyllum are taller than the shade-tolerant trees, so canopy density is not yet shading out the species. The greater size of the species could also be related to more beneficial growth conditions when the trees were established and current urban influences impacting development in Balch.

As previously mentioned, T. heterophylla in Balch are growing more slowly, which may account for the difference in size between the plots. A greater presence of non-native invasive species, human traffic linked to soil compaction, and hypothesized soil quality limitations, could restrict T. heterophylla size in Balch. Additionally, stand density would not impact $T$. heterophylla growth as much in Miller because the species is highly shade-tolerant. Again, an exploration of the soil profile is necessary to further probe influences on tree size difference between stands.

\section{Spatial Structuring in the Balch and Miller Stands}

The semivariogram results indicate that little to no spatial structuring currently exists in the Miller and Balch stands. In Balch, there is some evidence of spatial relation for dbh at ten meters, but the correlation immediately declines with distance. However, research indicates that horizontal and vertical diversification take a long time to develop. Franklin et al. (2002) specify that it is not until a stand is $100-150$ years old that spatial structure begins to become more heterogeneous.

The results from this exploration of spatial patterning in Balch and Miller validate the assumption that stand complexity takes a long time to develop. The oldest 
tree dated in Balch was 109, while Miller's oldest tree was 135. Those ages indicate that the stand is just reaching a point for structural complexity to begin to develop. Referencing the Franklin et al. (2002) succession theory, both stands are reaching a period of maturation, and will continue to get more complex as time goes on. However, the role of urban impacts and the lack of recruitment in Balch, may complicate the succession of the stand, resulting in a composition different than what is expected for T. heterophylla zone. The implications spatial complexity, non-native invasions, shade-tolerant recruitment, and stand regulation are important for management in Forest Park.

\section{Implications \& Management in Forest Park Stands}

Old growth $T$. heterophylla and T. plicata forests are one of the most heavily altered ecosystems in the Pacific Northwest. As old growth forest habitat has declined, there have been major consequences for several old-growth obligate species, as well as for habitat connectivity throughout the region. There have also been consequences regarding the ability for forest stands to self-regulate in the absence of late succession species. Since Forest Park is managed as a natural forest system, the area is in a position to contribute to the regeneration of old growth forest stands in the region. It is unlikely that the park will be logged, so managing for old growth conditions will contribute to rebuilding an ecosystem that has been greatly diminished, and provide habitat for the various species dependent on it.

The Miller plot currently validates the Franklin et al. (2007) succession theory and appears to be on track for achieving old growth conditions. The reverse J-curve presented in Figure 4.13 evidences successful shade-tolerant recruitment and the 
potential for self-regulation in the stand. The Balch plot, on the other hand, needs to be more closely managed if old growth is desired. The Balch plot does not exhibit a reverse J-curve pattern or much shade-tolerant success. A concentrated effort in promoting recruitment in Balch is needed for increasing late succession populations.

Forest Park has only one ranger to patrol over 5,000 acres of park. Consequently, it is difficult to monitor off trail activities throughout the entire natural area. Evidence from this investigation indicates that management resources, like enforcing rules regarding off trail use, are most needed in the more heavily used Balch watershed. Management should consider surveying the highly trafficked Balch drainage for illegal and unmanaged trails, like those in Figure 4.22. Locating commonly used, unregulated trails may help reduce off trail traffic and associated soil compaction and trampling. Most notably, the non-native invasions in Balch need to be managed for stand regulation. Even if old growth conditions are not desired in all areas of Forest Park, the invasion of H. helix in Balch needs to be managed to avoid a broad-scale reduction of biodiversity.

Although management in Forest Park takes a "protect the best" approach, it is important to continue protecting areas that do not exhibit desired ecological conditions. The Miller drainage appears to be in "the best" condition and park management should continue efforts to keep invasions and increased traffic minimized. However, park management should also continue to support removal of non-native invasions in the Balch drainage, and employ practices that promote shadetolerant and native recruitment. Whether it means actively planting native species, or 
removing threats to recruitment success, Forest Park managers should not only protect the best, but support rehabilitation of the stressed stands.

\section{Limitations of this study \& recommendations for future data collection}

A major limitation of this study on the 2010 permanent plot data is that plot selection was not random, and thus statistical testing is difficult. However, it is unlikely that truly random sampling is achievable throughout Forest Park, since it is a topographically and compositionally heterogeneous landscape. Although future research may be restricted in statistical tests, statistical analysis is still possible. Additionally, it is not known if the size of our plots is representative of the drainages in which they were installed. The diverse topography and composition of Forest Park makes multiple sites necessary, but that should be remedied with future plot installments. Also, the coupling of data from other studies occurring in the park will be beneficial. Another limitation for the analysis of urban impacts is a lack of specific use reports, air quality readings, and temperature measurements for the plots.

In order to gather more data regarding urban influence on the plots, $\mathrm{HOBO}$ temperature loggers were installed in the plots and data has been collected for nearly a year. Using the temperature data will provide for a richer analysis of urban influences in the plots. In addition, recreational uses of the drainages will have to be more closely monitored. Ideally, air quality monitors would also be installed in the sites to get readings on possible atmospheric influences related to impacts from urban activities. This study is limited in pinpointing specific urban effects that may be at work in the

plots. Unquestionably, the soil profile in the current permanent plots and that in future installed plots will have to be analyzed as well. Soil characteristics, including nutrient 
loads, porosity, and structure must be explored for a better understanding of tree growth and condition.

Finally, determining stand age and growth rates is somewhat limited in this study. In order to garner a more accurate age of the stand, cores will need to be taken from T. plicata. Cores have been taken for many A. macrophyllum, but accurate dates will need to be determined from the porous wood. Also, measuring growth per individual year and creating a chronology will provide insight into specific growth patterns in the plots. This exploration, however, does provide a baseline for future inquiries and there are several courses of action that can now be taken for continued long-term research.

\section{Future research in Forest Park}

Additional research has already begun in Forest Park with the installation of more plots in old-growth sections near the park. The recent addition of more plots will help with an investigation into the lack of late-succession establishment observed in the Balch plot. Including more plots along a distance transect from urban Portland, will elucidate if, in fact, there is a continuum of urban influence on ecological processes. Testing whether or not there is a correlation between the soil profile and seeding establishment will also shed light on succession processes in the park. Furthermore, more specific research on recreational use in the drainages would address questions about specific urban influences at work.

Tracking park usage, including activities that may occur illegally, will be important to understanding events that may contribute to ecological degradation in the park. For example, locating unmanaged mountain bike trails and transient camps will 
provide excellent sites for ecological research on how the activities impact vegetation growth in the park. Comparing the information gathered from the Balch and Miller plots will give future studies a detailed reference point for conditions under varied traffic regimes. Prospective research should also include probing how Forest Park fits into the larger ecological region.

Although this study was a ground-based study, a future investigation could couple data collected from the permanent plots with satellite imagery of Forest Park. Similar to the Cohen et al. (2002) and Zhou et al. (2011) studies, satellite imagery could be used to monitor patch change and forest connectivity to the Oregon Coastal Range over time. A satellite imagery analysis could also be used to monitor changes in edge along the park and disturbance over broader spatial and temporal scales.

Atmospheric influences on Forest Park will also be important to investigating the urban impacts on park processes. Research regarding atmospheric influences on tree growth often occurs in highly controlled environments. Installing air quality monitors along the urban-rural gradient in Forest Park could be used to explore how temperature and atmospheric carbon constituents affect physiological responses in natural stands. Finally, a reclassification of successional stages and species populations could be conducted to compare to Houle's 1982 study. Exploring successional stages, bird, and mammal populations, and comparing them to data from nearly 30 years ago may provide a window into how Forest Park has changed on a short temporal scale. It would also provide a look into current and potential habitat for wildlife residing in the park. Unquestionably, there is huge potential for Forest Park to 
serve as a unique resource for research on the urban forest, and in particular on how urbanization affects natural systems. 


\section{CHAPTER 6: CONCLUSION}

In 2004, the National Urban and Community Forestry Advisory Council (NUCFAC) produced a ten-year plan that is designed to foster research in urban forestry. Emphasizing six strategic goals, the NUCFAC plan strives to more fully explore and understand the many facets, processes, and ecological services of urban forests. This investigation in particular, tackled two NUCFAC goals, the first promoting the expansion of knowledge and innovation regarding urban resource management, and encouraging urban ecosystem health and sustainability (Clark et al. 2005).

By exploring stand composition in Forest Park, this project contributes to the expansion of knowledge regarding urban resource management. The exploration of tree growth and spatial pattern in the park is now available to park and city managers to aid in decision-making. The information can also help shape policy and management practices in order to reduce detrimental landscape change over time.

The ongoing investigation into the status of Forest Park addressed a second NUCFAC strategic goal regarding the need to "assess and monitor changing land use, to develop policy and practices to reduce landscape change," (Clark et al. 2005). Exploring the baseline data collected in the first year of plot establishment, and continuing to monitor the trees in the Forest Park plots, provides insight into how land use and disturbance may influence arboreal spatial pattern and growth in an urban forest.

In order to understand the potential effects and changes that are occurring in Forest Park, and look forward to the changes that it may undergo, stand composition 
and condition must be quantified and tracked. This investigation provides an initial picture of select forest stands in the park. It also elucidates the potential land use impacts, historical and present, that may be shaping Forest Park ecology. Similar to the Broshot (2009) conclusions, the urban Balch site exhibits different stand characteristics, in tree density and recruitment, than the more rural Miller. This study also supports findings from several other investigations on how historical and presentday land uses can influence the composition and spatial patterning of forest stands (Foster \& Aber 2004, Scheller \& Mladenoff 2002, Zhou et al. 2011). Although the specific urban influences that may be at work, along with the resultant ecological impacts, need more investigation, this exploration provides a starting point. As the long-term exploration of Forest Park continues, we will better understand how land use actions, past and present, shape Portland's forested reserve. 


\section{REFERENCES}

Apple, M.E., Olszyk, D.M., Ormrod, D.P., Lewis, J., Southworth, D., \& Tingey, D.T. (2000). Morphology and Stomatal Function of Douglas Fir Needles Exposed to Climate Change: Elevated $\mathrm{CO}_{2}$ and Temperature. International Journal of Plant Sciences 161(1): 127-132.

Bailey, J.D. (1996). Effects of stand density reduction on structural development in western Oregon Douglas-fir forests - a reconstruction study. (Doctoral dissertation). Oregon State University, Corvallis.

Bazzaz F.A. (1990) The response of natural ecosystems to the rising $\mathrm{CO}_{2}$ levels. Annual Reviews of Ecology and Systematics 21: 167-196.

Boersma, P.D. \& Van Buren A.N., eds. (2006). Invasive Species of the Pacific Northwest.

Broshot, N. (2007). The influence of urbanization on forest stand dynamics in Northwestern Oregon. Urban Ecosystems, 10: 285-298.

Broshot, N. (2009). Linfield College, Professor of Biology. Personal Communication, November 2009.

City Club of Portland. (2010). Forest Park: A Call to Action. Portland, Oregon. Retrieved from www.pdxcityclub.org.

Clark, J., Kruidenier, W., \& Wolf, K. (2005). National Research Plan for Urban Forestry: 2005-2015.

Craul, P.J. (1994). Soil compaction on heavily used sites. Journal of Arboriculture 20(2): 69-74. 
Deshler, J. (2010). Nest-site Habitat Selection and Breeding Biology of the Northern Pygmy-owl in Northwestern Oregon. (Unpublished Masters Thesis). Portland State University, Portland, Oregon.

De Voto, B., ed. (1953). The Journals of Lewis and Clark. Houghton Mifflin, Boston, MA.

Dlugosch, K.M. (2005). Understory community changes associated with English ivy invasions in Seattle's urban parks. Northwest science 79(1): 52-59.

Dwyer, J.F., Norwak, D.J., \& Noble, M.H. (2003). Sustaining urban forests. Journal of Aboriculture 29(1): 49-55.

Escobedo, F.J. \& Nowak, D.J. (2010). Spatial heterogeneity and air pollution removal by an urban forest. Landscape and Urban Planning 90: 102-110.

Forest Park Conservancy. (2011). Forest Park Conservancy Annual Trails Report for 2010-2011. Portland, Oregon.

Forest Park Ivy Removal Project (2008). Alien Invaders: The Dirty Thirty: Invasive Species of Greatest Concern in Forest Park. Retrieved from http://www.portlandonline.com/parks/index.cfm?c=47820

Foster, D.R. \& Aber, J.D. (2004). Forests in Time: The Environmental Consequences of 1,000 Years of Change in New England. New Haven, NJ: Yale University Press.

Franklin J. F. \& Dyrness C.T. (1988). Natural vegetation of Oregon and Washington. Corvallis, OR: Oregon State University Press.

Franklin, J.F., Spies, T.A., Van Pelt, R., Carey, A.B., Thornburgh, D.A., Berg, D.R., Lindenmayer, D.B., Harmon, M.E., Keeton W.S., Shaw, D.C., Bible, K., \& 
Chen, J. (2002). Disturbances and structural development of natural forest ecosystems with silvicultural implications, using Douglas-fir forests as an example. Forest Ecology \& Management 155: 299-423.

Groffman, P.M. \& Pouyat, R.V. (2009). Methane uptake in Urban Forests and Lawns. Environmental Science and Technology 43: 5229-5235.

Halpern, C.B. \& Spies, T.A. (1995). Plant species diversity in natural and managed forests of the Pacific Northwest. Ecological Applications 5(4): 913-934.

Houle, M.C. (1982). One City's Wilderness: Its Wildlife and Habitat Interrelationships. (Unpublished master's thesis). Oregon State University, Corvallis, Oregon.

Houle, M.C. (1996). One City's Wilderness, $2^{\text {nd }}$ Edition. Portland, OR: The Oregon Historical Society.

Kozlowski, T.T. (1986). Soil Aeration and Growth of Forest Trees. Scandinavian Journal of Forest Research 1(1-4): 113-123.

Kozlowski, T.T. (1999). Soil Compaction and Growth of Woody Plants. Scandinavian Journal of Forest Research 14(6): 596-619.

Kuhn, D. (2005). Fire in Forest Park. (Unpublished Masters Thesis). Portland State University, Portland, Oregon.

Lewis, J.D., Olszyk, D., \& Tingey, T. (1999). Seasonal patterns of photosynthetic light response in Douglas-fir seedlings subjected to elevated atmospheric CO2 and temperature. Tree Physiology 19: 243-252.

Munger, T. (1960). History of Portland's Forest Park. Portland, OR: Forest-Park Committee of Fifty. 
Nilsen, F. (2011). Portland Parks \& Recreation, Retired City Parks Manager. Personal Communication, March 2011.

No Ivy League. (2005). Decennial Monitoring Report 1994-2004. Portland, OR.

Ormrod, D.P., Lesser, V.M., Olszyk, D.M., \& Tingey, D.T. (1999). Elevated Temperature and Carbon Dioxide Affect Chlorophylls and Carotenoids in Douglas-Fir Seedlings. Journal of Plant Sciences 160(3): 529-534.

Pataki, D.E., Alig, R.J., Fung, A.S., Golubiewski, N.E., Kennedy, C.A., Mcpherson, E.G., Nowak, D.J., Pouyat, R.V., and P.R. Lankao (2006) Urban ecosystems and the North American Carbon Cycle. Global Change Biology 12: 20922102.

Portland Parks and Recreation (2010). Forest Park. Retrieved from http://www.portlandonline.com/parks/finder/index.cfm?PropertyID=127\&actio $\mathrm{n}=$ ViewPark.

Portland State University. (2010). Proceedings from the First Forest Park Research Colloquium. Portland, OR: Portland State University.

Quigley, M.F. (2002). Franklin Park: 150 years of changing design, disturbance, and impact on tree growth. Urban Ecosystems 6: 223-235.

Ruiz, G.M. \& Carlton, J.T., eds. (2003). Invasive Species: Vectors and Management Strategies. Washington D.C.: Island Press.

Scheller, R. M. \& Mladenoff, D. J. (2002). Understory species patterns and diversity in old growth and managed northern hardwood forests. Ecological Applications 12(5): 1329-1343. 
Schwartz, M.W., Porter, D.J., Randall, J.M., \& Lyons, K.E. (1996). Impact of Nonindigenous Plants.

Spies, T.A. \& Franklin, J.F. (1991). The Structure of Natural Young, Mature, and OldGrowth Douglas-Fir Forests in Oregon and Washington. USDA Forest Service General Technical Report PNW-GTR, Pacific Northwest Research Station (285): 91-109.

Swanson, F.J. \& Franklin, J.F. (1992). New Forestry Principles from Ecosystem Analysis of Pacific Northwest Forests. Ecological Applications 2:262-274.

Swetnam, T.W., Allen, C.D., \& Betancourt, J.L. (1999). Applied Historical Ecology: Using the Past to Manage for the Future. Ecological Applications, 9(4): 11891206.

Tappeiner, J.C., Huffman, D., Marshall, D., Spies, T.A., \& Bailey J.D. (1997). Canadian Journal of Forestry Research 27: 638-648.

Vitousek, P.M., D’Antonio C.M., Loope, L.L., Rejmanek, M.R., \& Westbrooks, R. (1997). Introduced species: a significant component of human caused global change.

Washington State Department of Natural Resources (DNR). (2009). Washington Timber Harvest 2009. (Published by the Washington State Department of Natural Resources). Olympia, WA: Government Printing Office.

Watson, R.T., Noble, I.R., Bolin, B., Ravindranath, N.H., Verardo, D.J., \& Dokken, D.J. (Eds.) (2000). Land Use, Land-Use Change, and Forestry (A special report of the Intergovernmental Panel on Climate Change). Cambridge University Press. 
Winter, L.E., Brubaker, L.B., Franklin, J.F., Miller, E.A., \& DeWitt, D.Q. (2002). Initiation of an old-growth Douglas-fir stand in the Pacific Northwest: a reconstruction from tree-ring records. Canadian Journal of Forest Research 32: 1039-1056.

Zhou, W., Huang, G., Steward, Pickett, T.A., \& Cadenasso, M.L. (2011). 90 years of forest cover change in an urbanizing watershed: spatial and temporal dynamics. Landscape Ecology 26: 645-659. 